Ulrike Einhorn-Stoll, Hanna Kastner, Alexandra Fatouros, Andrea

Krähmer, Lothar W. Kroh, Stephan Drusch

\title{
Thermal degradation of citrus pectin in low-moisture environment - Investigation of backbone depolymerisation
}

Journal article | Accepted manuscript (Postprint)

This version is available at https://doi.org/10.14279/depositonce-11860

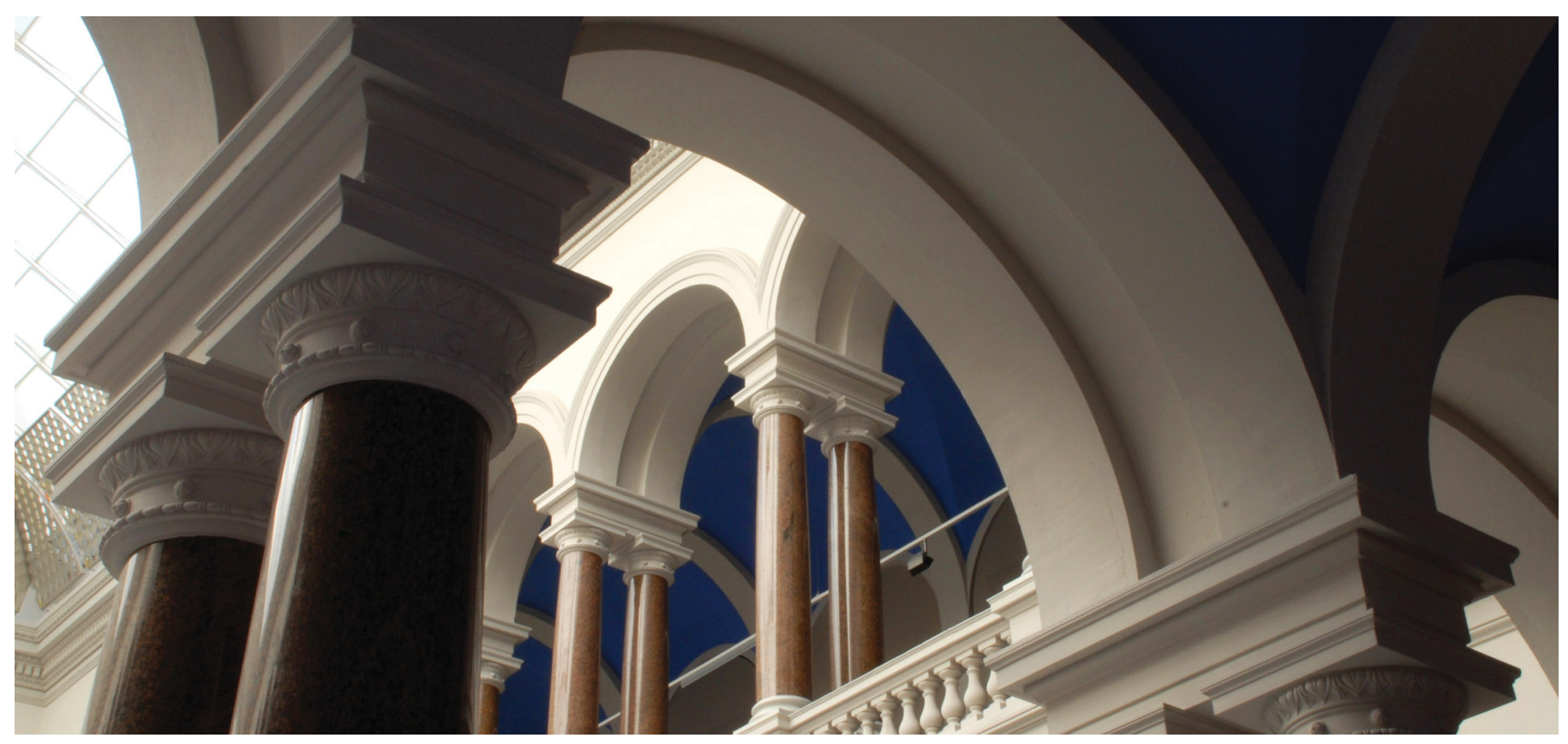

Einhorn-Stoll, U., Kastner, H., Fatouros, A., Krähmer, A., Kroh, L. W., \& Drusch, S. (2020). Thermal degradation of citrus pectin in low-moisture environment - Investigation of backbone depolymerisation. Food Hydrocolloids, 107, 105937. https://doi.org/10.1016/j.foodhyd.2020.105937 


\title{
Thermal degradation of citrus pectin in low-moisture environment - Investigation of backbone depolymerisation
}

Ulrike Einhorn-Stoll ${ }^{1}$, Hanna Kastner ${ }^{1}$, Alexandra Fatouros ${ }^{2}$, Andrea Krähmer3, Lothar W. Kroh², Stephan Drusch ${ }^{1}$

${ }^{1}$ Technische Universität Berlin, Department of Food Technology and Food Material Sciences, Germany

${ }^{2}$ Technische Universität Berlin, Department of Food Chemistry and Analytics, Germany

3 Institute for Ecological Chemistry, Plant Analysis and Stored Product Protection (Julius-Kühn-Institut, Berlin), Germany

\begin{abstract}
Thermal degradation of modified pectin samples with varying molecular structure during storage was recently studied at $60{ }^{\circ} \mathrm{C}$ and $80 \%$ relative humidity (rh) for 28 days. Demethoxylation and depolymerisation were identified as main degradation reactions. The present paper aims on improving the understanding of the different depolymerisation reactions and their interplay with demethoxylation during storage. Therefore, thermal degradaton of acidic and alkaline demethoxylated pectins was studied at a further reduced $\mathrm{rh}$ of $40 \%$. The alterations were examined in detail via molecular parameters and were reflected by Differential scanning calorimetry and attenuated total reflectance Fourier-transformation infrared spectroscopy. The impact of thermal degradation on pectin particle structure was studied via particle surface area and microscopy.

At low relative humidity ( $\mathrm{rh}$ ) demethoxylation and depolymerisation were reduced, and the formation of brown reaction products, resulting from further decomposition of intermediate uronides and neutral sugars, was restricted. By comparing thermal degradation at different humidity, eliminative decarboxylation was identified as the main depolymerisation reaction.

Reduction of rh affected also the alteration of pectin material properties, particle surface reduction was less pronounced. Molecular alterations were stronger in case of acidic demethoxylated samples, and alterations of material properties were higher in case of alkaline demethoxylated samples.
\end{abstract}




\section{$1 \quad$ Introduction}

Citrus pectin is used as thickening and gelling agent in a wide range of foods. Its functionality is governed by the molecular structure. On the one hand, we take advantage of this when modifying pectin by chemical or enzymatic treatment to adapt it to specific applications (Endress, 2011; Rolin, Chrestensen, Hansen, Staunsstrup, \& Sorensen, 2010; Rolin, 2002). On the other hand, technofunctionality may be affected by unintended degradation of the molecular structure as it may occur as a side reaction during processing, modification or storage. Degradation caused by heat or storage at elevated temperature is referred to as "thermal degradation" or "thermolysis". Thermolysis takes place in solution, as studied by many authors (e.g. Diaz, Anthon, \& Barrett, 2007; Fraeye et al., 2007; Krall \& McFeeters, 1998; Renard \& Thibault, 1996; Axelos \& Branger, 1993; Sajjaanantakul, Van Buren, \& Downing, 1993; Kravtchenko, Arnould, Voragen, \& Pilnik, 1992; Van Buren, 1979; Keijbets \& Pilnik, 1974; BeMiller \& Kumari, 1972). However, thermolysis may also occur in dry pectin samples for instance during storage or transport. This phenomenon was first described by Padival, Ranganna \& Manjrekar (1981).

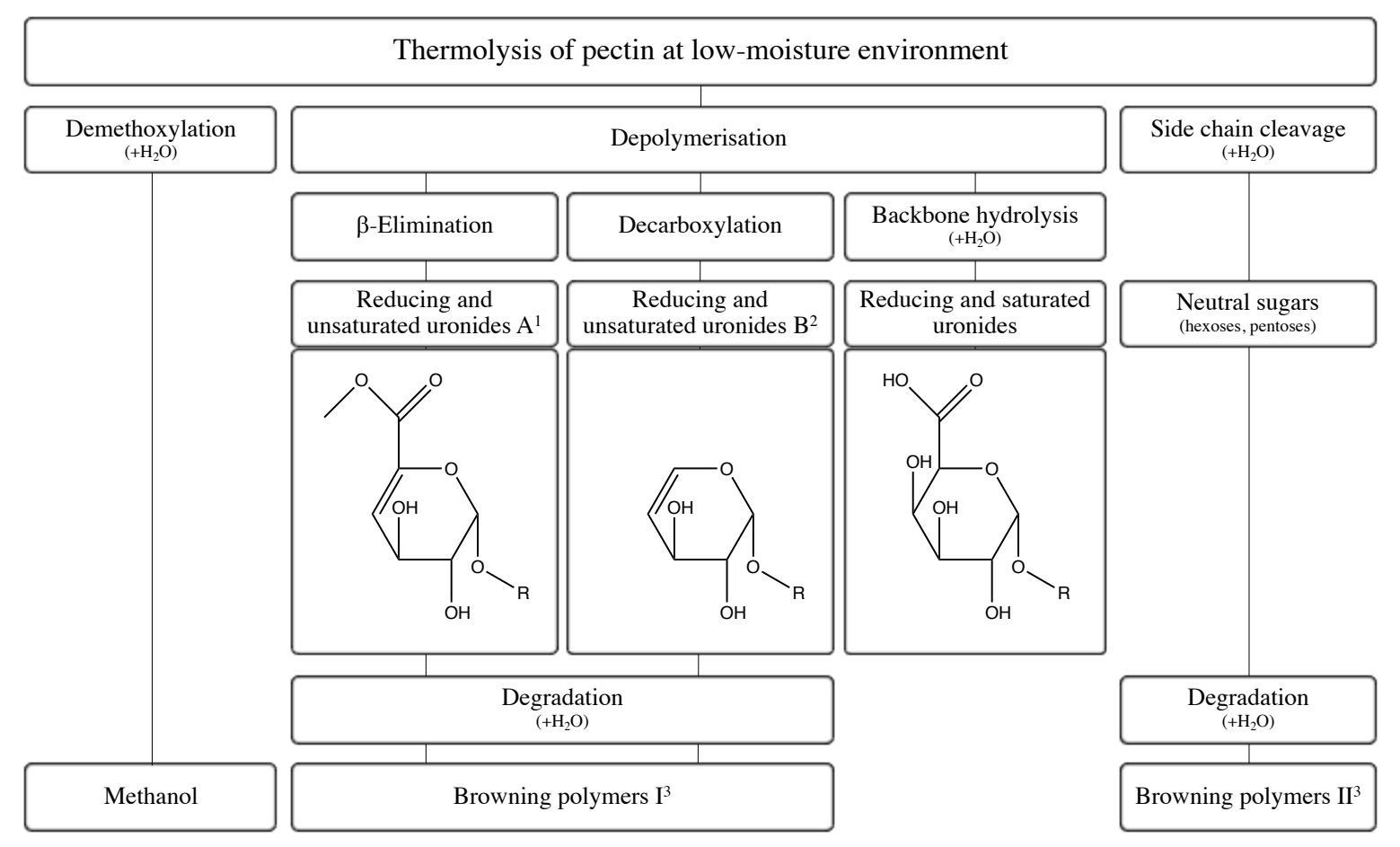

Fig. 1: Overview of reactions during thermal degradation of pectins in a climate chamber. ${ }^{1}$ Unsaturated uronides $A$ contain an ester group at C6. ${ }^{2}$ Unsaturated uronides B lost their carboxyl group at C6 due to decarboxylation. 3 Degradation of uronides or neutral sugars results in different browning polymers I and II. $-R$ represent neighboured GalA molecules forming the oligogalacturonides.

Thermolysis is a complex of reactions acting at different sites of the pectin molecule and, thus, results in a variety of degradation products (Fig. 1). The principal knowledge about the general degradation reactions of pectin was reviewed in a recent publication of our group (Einhorn-Stoll, 
Kastner, Urbisch, Kroh, \& Drusch, 2019). The more specific knowledge on thermolysis of pectin in low moisture environment may be summarised as follows:

- Demethoxylation, depolymerisation by backbone hydrolysis and cleavage of neutral sugar side chains require water. Consequently, these reactions are directly affected by the moisture content and, thus, by the relative humidity of the environment. In contrast, depolymerisation via $\beta$ elimination and depolymerisation by eliminative decarboxylation do not require water, but may be indirectly affected by the reactions mentioned above.

- The individual contribution of the three depolymerisation reactions is not completely understood. We postulated that $\beta$-elimination and eliminative decarboxylation were the dominating depolymerisation reactions during thermal pectin degradation. Their intensity depends on the structure of the pectin, resulting from modification by chemical or enzymatic demethoxylation. $\beta$-elimination is favoured at a high degree of methoxylation (DM) whereas eliminative decarboxylation dominates at low DM. Some authors (BeMiller \& Doyle, 1971; Timell, Enterman, Spencer, \& Solters, 1965) assume that backbone hydrolysis is nearly impossible due to an inhibiting effect of the ester groups at $\mathrm{C} 6$ of the galacturonic acid (GalA).

- Neutral sugar side chains are cleaved from the pectin backbone by hydrolysis. A high content of neutral sugar reduces demethoxylation, since both reactions compete for water and in that case side chain cleavage is favoured (Axelos \& Branger, 1993; van Buren, 1979).

- Intermediate reaction products of all depolymerisation reactions are reducing sugars. In case of $\beta$-elimination and decarboxylation (but not in case of backbone hydrolysis) unsaturated uronides are formed (Diaz et al., 2007), which are further decomposed to various coloured reaction products (Bornik \& Kroh, 2013) and cause browning. Browning is increased by the cooccurring degradation of neutral sugar molecules cleaved from the side chains (Urbisch, Einhorn-Stoll, Kastner, Drusch, \& Kroh, 2018; Bornik \& Kroh, 2013). At least some steps of the decomposition of uronides and neutral sugars require water, (Fig. 1).

- Storage may not only alter the molecular structure but also the material properties of dried pectin powder such as particle form, surface and microstructure. The surface of the pectin particles is softened and smoothed, particles agglomerate and the BET-surface decreases as was found before (Einhorn-Stoll, Benthin, Zimathies, Görke, \& Drusch, 2015).

Our group studied thermal degradation of pectin in a low moisture environment in model systems at $60{ }^{\circ} \mathrm{C}$ and 80\% rh (Einhorn-Stoll et al., 2019; Einhorn-Stoll, Kastner, \& Drusch, 2014; EinhornStoll, Prinz, \& Drusch, 2014; Einhorn-Stoll \& Kunzek, 2009). Water uptake of the pectin samples during 28 days at $80 \%$ rh was about $5 \%$, and the final water content was approximately $10 \%$. Although this value is low, it still allowed water-depending degradation reactions to occur. Recent work (Einhorn-Stoll et al., 2019) focused on the experimental verification of eliminative decarboxylation as possible depolymerisation mechanism. The results strongly supported the idea of this reaction, since the other two depolymerisation mechanisms, backbone hydrolysis and $\beta$ - 
elimination, were insufficient for explaining the degradation intensity. A direct verification of eliminative decarboxylation will be the subject of a separate investigation. The intention is to measure the released carbon dioxide during thermal degradation, and the results will be published elsewhere.

The present study aimed on a better understanding of the depolymerisation process during storage, in particular on the possible contributions of the three reactions backbone hydrolysis, $\beta$-elimination and eliminative decarboxylation. Since only the first of them requires water, a reduction of relative humidity and, thus, of the moisture content of the sample should differently affect the single reaction types. In particular, an impact of a lower extent of demethoxylation (due to lower water supply) on the dominating type(s) of backbone depolymerisation was expected. Moreover, browning as well as physical alteration of pectin material properties, in particular the BET-surface area of the pectin powder particles, were assumed to be limited by a lower rh, and therefore they were studied in the present work. To fulfil the aim, degradation and browning of four well defined pectin samples, prepared by acidic and alkaline demethoxylation and each with two different DM, were tested in an environment with a strongly restricted rh of $40 \%$. Comparison with the course of the degradation at $80 \%$ rh should help to identify the contribution of the individual reactions to backbone depolymerisation. Samples were analysed for DM, molecular weight and colour as described recently (Einhorn-Stoll et al., 2019). In addition, ATR-FTIR spectroscopy was applied for characterization of intermediate and final degradation products such as GalA or neutral sugars, based on characteristic absorption patterns in the fingerprint area of the spectra below $1000 \mathrm{~cm}^{-1}$ (Kakuráková et al., 2000; Coimbra, Barros, Barros, Rutledge, \& Delgadillo, 1998). The total content of unsaturated uronides was analysed by measuring the absorption at $235 \mathrm{~nm}$ (Diaz et al., 2007; Krall \& McFeeters, 1998; Kravtchenko, Voragen, \& Pilnik, 1992). An increase of the $A_{235}$ during storage reflects the formation of unsaturated reaction products as a result of depolymerisation. The material properties of the pectin particles were characterised by scanning electronic microscopy (SEM) and measurement of the BET-surface. 


\section{Materials and methods}

\section{$2.1 \quad$ Materials}

Pectin samples with different DM were prepared by acidic or alkaline demethoxylation from a highmethoxylated commercial citrus pectin (CP; kindly provided by Herbstreith \& Fox KG, Neuenbürg, Germany) with a DM of $71 \%$ as recently described (Einhorn-Stoll et al., 2019). Acidic demethoxylation was performed at room temperature using $2 \mathrm{M} \mathrm{HCl}$, and alkaline demethoxylation by pH-stat method at $5{ }^{\circ} \mathrm{C}$ and $\mathrm{pH} 11.5$ using $0.5 \mathrm{M} \mathrm{NaOH}$. High-methoxylated pectin (HMP-A) and low-methoxylated pectin (LMP-A) prepared by acidic treatment (A-pectins) were the same as used for the study at $80 \% \mathrm{rh}$, whereas samples from alkaline treatment (HMP-AL and LMP-AL, named as AL-pectins) were freshly prepared as described in the above mentioned reference. All chemicals and solvents used were of analytical grade.

\subsection{Methods}

\subsubsection{Thermal degradation - Thermolysis}

All samples were stored in a climate chamber with a controlled humidity system (KBF 115, Binder, Tuttlingen, Germany) for four weeks. The temperature was kept at $60{ }^{\circ} \mathrm{C}$ to accelerate degradation and to achieve a well-detectable extent of degradation within a reasonable time. It has been reported that higher temperature favoured all tested degradation reactions (Einhorn-Stoll \& Kunzek, 2009). HMP-A and LMP-A were stored at $40 \% \mathrm{rh}$, and the results were compared to those of the recent study performed at 80\% rh (Einhorn-Stoll et al., 2019), HMP-AL and LMP-AL were stored at 40\% as well as $80 \% \mathrm{rh}$. Individual samples for analyses were taken at the beginning of storage and after 7 , 14, 21 and 28 days. After removal from the climate chamber, samples were dried at room temperature in a desiccator for $24 \mathrm{~h}$ in order to remove adsorbed water and finally stored at $-10{ }^{\circ} \mathrm{C}$ prior analysis.

\subsubsection{Characterisation of pectin}

Pectin characterisation was performed using the methods described in the recent publication (Einhorn-Stoll et al., 2019), all analyses were performed in duplicate. Free galacturonic acid content (GC) and DM were determined by photometric methods. The $m$-hydroxydiphenyl method (Blumenkrantz, \& Asboe-Hansen, 1973) was applied for the determination of GC. The chromotropic acid method (Bäuerle, Otterbach, Gierschner, \& Baumann, 1977) was used for determination of the DM. In brief: Dissolved pectin is saponified with sodium hydroxide, methanol is released and isolated by distillation. The distillate is mixed with potassium permanganate and sodium sulfite, chromotropic acid is added, and the solution is heated. A coloured reaction product is formed, and absorption is measured at $570 \mathrm{~nm}$. DM is calculated as mmol released methanol / mmol galacturonic acid. 
The intrinsic viscosity ([ๆ]) was analysed at $20{ }^{\circ} \mathrm{C}$ using a rolling ball micro viscometer LOVIS 200oM (Anton Paar GmbH, Ostfildern-Scharnhausen, Germany) as described recently (Kastner, Einhorn-Stoll, \& Drusch, 2019). Analysis was performed in duplicate with 16 data points per determination. The molecular weight (MW) distribution was characterised qualitatively by gel permeation chromatography (GPC), using parameters and instruments as described by Wegener, Kaufmann, \& Kroh (2017). The samples were dissolved in distilled water and a RI-detector was used for monitoring the effluent. Calibration was performed using a Pullulan kit (PSS-pulkit, PSS Polymer Standards Service GmbH, Mainz, Germany), containing standards of 1, 5, 20, 100 and $400 \mathrm{kDa}$. The following fractions were detected: elution time $15 \mathrm{~min} \approx 380 \mathrm{kDa}, 17 \mathrm{~min} \approx 100 \mathrm{kDa}$, $19 \min \approx 12 \mathrm{kDa}$ and $21 \mathrm{~min} \approx 0.3 \mathrm{kDa}$.

Finally, the sodium content was determined from the ash (prepared in a muffle furnace at $550{ }^{\circ} \mathrm{C}$ ) by flame photometry using a PerkinElmer AAnalyst ${ }^{\mathrm{TM}} 800$ (Rodgau, Germany) using acetylene/air gas mixture. All analyses were performed in duplicate.

\subsubsection{Identification of unsaturated uronides}

Unsaturated uronides are reaction products of depolymerisation by $ß$-elimination or eliminative decarboxylation. The content was screened by UV/VIS spectroscopy at $235 \mathrm{~nm}\left(\mathrm{~A}_{235}\right)$ using a Pharmacia Ultrospec ${ }^{\mathrm{TM}} 1100$ pro UV/VIS photometer (Amersham Pharmacia, Amersham, UK). For analyses, a solution of $0.2 \%$ pectin in distilled water was prepared. Samples were stirred for $24 \mathrm{~h}$ at room temperature in order to achieve complete dissolution and filtered through a micro filter $(1 \mu \mathrm{m}$ pore size). In case the absorption was higher than one absorption unit, the samples were diluted with $50 \%$ distilled water.

\subsubsection{Thermal analysis to monitor degradation of pectin}

Simultaneous thermal analysis reflects the degradation and allows a rapid evaluation of its extent (Einhorn-Stoll et al., 2019). Thermal analysis was carried out as combination of differential scanning calorimetry (DSC) and thermogravimetry (TG) using a STA 449 F3 Jupiter (Netzsch, Selb, Germany). Measurements were performed in duplicate in an inert helium atmosphere $(70 \mathrm{~mL} / \mathrm{min})$ with a linear heating rate $10 \mathrm{~K} / \mathrm{min}$ from 20 to $450^{\circ} \mathrm{C}$.

\subsubsection{ATR-FTIR analysis to monitor degradation of pectin}

ATR-FTIR spectra were recorded using a portable FTIR spectrometer Alpha 1 with a Platinum ATR single reflection diamond ATR device (Bruker Optik GmbH, Ettlingen, Germany). The sample spectra were acquired at room temperature between 400 and $4000 \mathrm{~cm}^{-1}$ with a spectral resolution of $4 \mathrm{~cm}^{-1}$. Powdered samples were used without further sample preparation and directly applied to the diamond crystal. The standard pressing mechanism of the instrument allowed a constant pressure for all measurements. All spectra were composed of 32 scans, and samples were measured in 
triplicate. Background spectra were recorded for each measurement, and background subtraction was performed for all spectra using instruments software (OPUS 7.2, Bruker Optik GmbH, Ettlingen, Germany).

\subsubsection{Colour formation and material properties}

Thermal degradation and subsequent reactions of the degradation products during storage result in browning. For colour determination, the dry samples were examined before and after thermal degradation with a Chromameter CR 300 (Minolta, Japan) using the CIELAB system (10 measurements per sample). An increase in positive a- (red) and b-values (yellow) indicates the increasing extent of browning reactions.

Scanning electron microscopy (SEM) was used to characterise the particle morphology before and after storage. Analyses were performed at the Center for Electron Microscopy (ZELMI) of the Technische Universität Berlin using a S-2700 scanning electron microscope (Hitachi, Tokyo, Japan) after sputtering the samples with gold.

Moisture sorption during storage leads to physical changes of the material. The BET-surface was determined with a surface area analyser "QUADRASORB" ${ }^{\mathrm{TM}}$ SI Automated Surface Area \& Pore Size Analyzer" (Quantachrome Instruments, Boynton Beach, USA) in order to detect these changes. BETsurface analysis was performed in the Institute of Chemistry, Chair of Functional Materials, of the Technische Universität Berlin. Samples were prepared by vacuum drying at room temperature for $24 \mathrm{~h}$. Measurements were performed in duplicate, using nitrogen as adsorptive agent with a relative pressure up to 0.25 bar, and using the Quantachrome's software QuadraWin for calculations. 


\section{Results and discussion}

Four pectin samples with two different DM were produced either by acidic (HMP-A/LMP-A) or alkaline demethoxylation (HMP-AL/LMP-AL). The DM was similar for the two HMP (59\% for HMP-A and 54\% for HMP-AL) and identical (37\%) in case of the two LMP (Table S1, supplementary material). The intrinsic viscosity was in a similar range $\left(550-600 \mathrm{~cm}^{3} / \mathrm{g}\right.$ ) for all samples except LMP-AL (465 $\mathrm{cm}^{3} / \mathrm{g}$ ) (Table S1). The lower intrinsic viscosity of this sample resulted from $\beta$ elimination during modification at pH 11, as discussed in detail before (Einhorn-Stoll et al., 2019). Unpublished data from our group show that such small differences in DM and intrinsic viscosity do not markedly alter the extent of thermal degradation. Within the following subchapters, first the course of the thermal degradation for samples stored for 7, 14, 21 and $28 \mathrm{~d}$ at $40 \%$ rh will be presented. Afterwards samples stored for $28 \mathrm{~d}$ at different rh (40 and $80 \%$ ) will be compared.

\subsection{Degradation at $40 \%$ rh}

The aim of the experiment on thermolysis at $40 \% \mathrm{rh}$ was to investigate the nature and extent of the degradation reactions under conditions of very limited moisture content. No water uptake of the pectins was observed during storage for $28 \mathrm{~d}$, the total water content of the samples remained constant at the initial value around $5 \%$.

Though demethoxylation requires water and despite the water supply at $40 \% \mathrm{rh}$ is low, the reaction occurred to a certain extent in all samples (Fig. 2, Table S1). It was more pronounced in samples modified under acidic conditions (A-pectins) than in alkaline modified samples (AL-pectins) due to the different neutral sugar content (5.1-6.8\% in A- and 8.2-8.8\% in AL-samples). In a low moisture environment, neutral sugar side chain cleavage is favoured over demethoxylation in the competition for water (Axelos \& Branger, 1993; van Buren, 1979) and, thus, the higher neutral sugar content of the AL-pectins restricted demethoxylation as discussed before (Einhorn-Stoll et al., 2019).

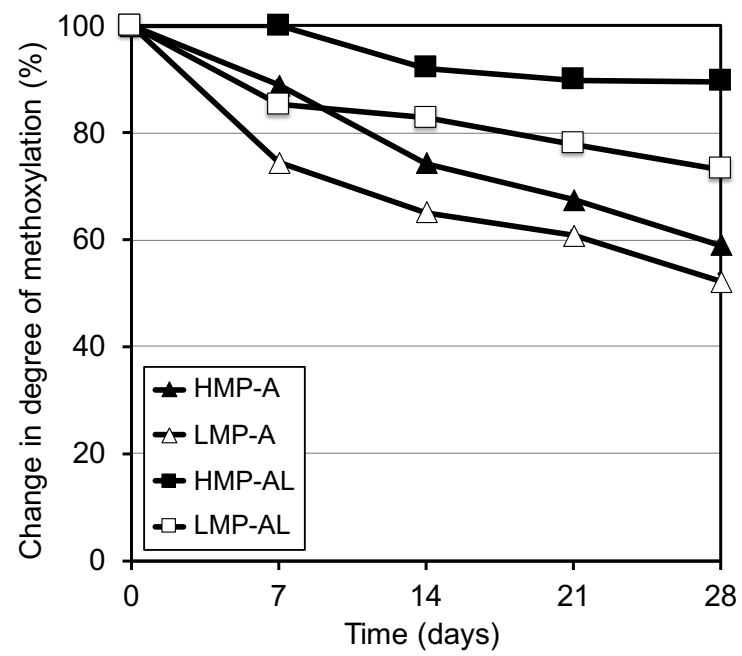

Figure 2: Decrease of degree of methoxylation (DM) during thermal degradation at 4O\% rh. HMP = high-methoxylated pectin, $L M P=$ low-methoxylated pectin, $-A=$ acidic modified $-A L=$ alkaline modified. 
Depolymerisation was found in all tested pectin samples. Reduction of intrinsic viscosity due to reduced molecular weight as well as the increase of absorption at $235 \mathrm{~nm}\left(\mathrm{~A}_{235}\right)$, resulting from formation of reaction products, were more pronounced in A- than in AL-pectins (Table 1, Fig. 3).

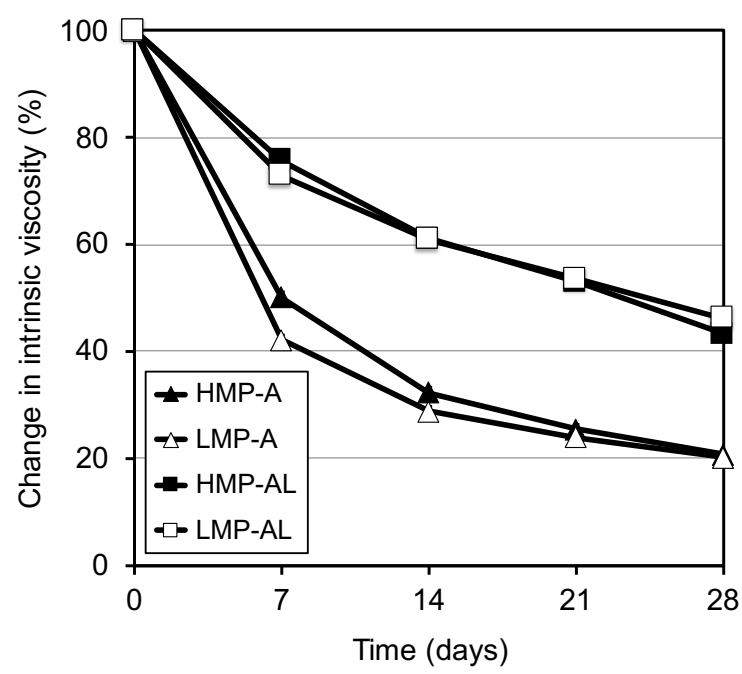

Figure 3: Decrease of intrinsic viscosity during thermal degradation at $40 \%$ rh. HMP = high-methoxylated pectin, LMP $=$ low-methoxylated pectin, $-A=$ acidic modified $-A L=$ alkaline modified .

The alteration of both parameters reflected a higher total extent of depolymerisation of the A-pectins. Depolymerisation by B-elimination should be similar in both pectin types, since this reaction is favoured by methoxyl groups and the DM was comparable for the two HMP and LMP, respectively (Table 1). Hence, the more pronounced depolymerisation of the A-pectins is likely to result from depolymerisation by eliminative decarboxylation and, to a low extent, from backbone hydrolysis. Both reactions require carboxyl groups (-COOH) without any substituents or associated monovalent cations (Einhorn-Stoll et al., 2019), and the number of such free carboxyl groups differed already in the modified pectin samples before storage. They are available in A-pectins, but they are mostly associated with sodium ions (forming carboxylate groups -COONa) in AL-pectins, since the content of sodium ions was < $0.01 \%$ in the A-pectins but $0.69 \%$ in HMP-AL and 1.99\% in LMP-AL. Eliminative decarboxylation and backbone hydrolysis of the AL-modified samples were restricted by the presence of sodium ions, as was proved in a parallel paper (Kastner, Einhorn-Stoll, Fatouros, \& Drusch, 2020). The two reactions were additionally limited for the AL-pectins by a lower formation of free $-\mathrm{COOH}$ by less intensive demethoxylation during storage in comparison to A-pectins. 
Table 1: Alterations of molecular parameters and material properties of the pectins during thermolysis. $r h=$ relative humidity, HMP = high-methoxylated pectin, $L M P=$ low- methoxylated pectin, $-A=$ acidic modified $-A L=$ alkaline modified. SDM = degree of methoxylation after, [ $\eta]$ 1/4 intrinsic viscosity, A235 = absorption of $0.2 \%$ pectin solution at $235 \mathrm{~nm}$, a-value/b-value 1/4 colour, BET = BET-surface. $D$ = deviation, means standard deviation for [ $\eta$ ] and $a$-/b-value or range for DM, A235 and BET. $\triangle$ means the value in \% related to the value before storage. The data for DM, [ $\eta$, a- and b-value of HMP-A and LMP-A at day o and day 28 80\% rh were already reported in Einhorn-Stoll et al., (2019)

\begin{tabular}{|c|c|c|c|c|c|c|c|c|c|c|c|c|c|c|}
\hline & day & rh (\%) & HMP-A & $D(+/-)$ & $\mathrm{D}(\%)$ & LMP-A & $D(+/-)$ & $\mathrm{D}(\%)$ & HMP-AL & $D(+/-)$ & $\mathrm{D}(\%)$ & LMP-AL & $D(+/-)$ & $\mathrm{D}(\%)$ \\
\hline \multirow{3}{*}{$\begin{array}{l}\text { DM } \\
(\%)\end{array}$} & o & & 59,4 & 0,10 & 100 & 37,2 & 0,90 & 100 & 54,1 & 0,90 & 100 & 37,2 & 0,40 & 100 \\
\hline & 28 & 40 & 35,0 & 0,30 & 59 & 19,4 & $0,1 O$ & 52 & 48,5 & 0,40 & 90 & 27,2 & $0,2 O$ & 73 \\
\hline & 28 & 80 & 7,6 & 0,10 & 13 & 3,6 & 0,10 & 10 & 17,8 & 0,20 & 33 & 15,0 & 0,20 & 40 \\
\hline \multirow{3}{*}{$\begin{array}{l}{[\eta]} \\
\left(\mathrm{cm}^{3} / \mathrm{g}\right)\end{array}$} & o & & 599 & 7,60 & 100 & 549 & 10,00 & 100 & 575 & 4,00 & 100 & 465 & 9,70 & 100 \\
\hline & 28 & 40 & 124 & 2,40 & 21 & 111 & 5,30 & 20 & 249 & 7,50 & 43 & 215 & 5,30 & 46 \\
\hline & 28 & 80 & 105 & 2,40 & 18 & 128 & 5,30 & 23 & 219 & 6,10 & 38 & 206 & 4,10 & 44 \\
\hline \multirow[t]{3}{*}{$\mathrm{A}_{235}$} & o & & 0,448 & 0,02 & 100 & 0,362 & $O, O O$ & 100 & 0,512 & 0,04 & 100 & 0,537 & $O, 01$ & 100 \\
\hline & 28 & 40 & 0,535 & 0,08 & 119 & 0,550 & $O, O O$ & 152 & 0,559 & $O, O O$ & 109 & 0,765 & $O, O O$ & 142 \\
\hline & 28 & 80 & 0,693 & 0,01 & 155 & 0,825 & $O, 01$ & 228 & 0,684 & 0,03 & 134 & 0,821 & $O, 01$ & 153 \\
\hline \multirow[t]{3}{*}{ a-value } & o & & 1,47 & 0,04 & 100 & 1,81 & 0,10 & 100 & 1,03 & 0,03 & 100 & 1,22 & 0,03 & 100 \\
\hline & 28 & 40 & 2,66 & 0,05 & 181 & 3,38 & 0,07 & 187 & 1,82 & 0,07 & 177 & 2,2 & 0,09 & 180 \\
\hline & 28 & 80 & 5,12 & 0,03 & 348 & 5,95 & 0,10 & 329 & 3,51 & 0,04 & 341 & 3,84 & 0,09 & 315 \\
\hline \multirow[t]{3}{*}{ b-value } & o & & 14,01 & 0,13 & 100 & 15,08 & 0,49 & 100 & 11,38 & 0,15 & 100 & 11,49 & 0,16 & 100 \\
\hline & 28 & 40 & 17,33 & 0,14 & 124 & 19,08 & 0,30 & 127 & 14,32 & 0,13 & 126 & 14,94 & 0,28 & 130 \\
\hline & 28 & 80 & 23,73 & 0,18 & 167 & 24,76 & 0,29 & 164 & 19,13 & 0,11 & 168 & 19,56 & 0,16 & 170 \\
\hline \multirow{3}{*}{$\begin{array}{l}\text { BET } \\
\left(\mathrm{m}^{2} / \mathrm{g}\right)\end{array}$} & o & & 0,801 & 0,05 & 100 & 0,672 & 0,04 & 100 & 2,728 & 0,01 & 100 & 5,350 & 0,03 & 100 \\
\hline & 28 & 40 & 0,571 & $O, 01$ & 71 & 0,494 & 0,04 & 74 & 1,275 & 0,04 & 47 & 1,576 & $O, 01$ & 29 \\
\hline & 28 & 80 & 0,344 & $O, 01$ & 43 & 0,344 & $O, 01$ & 51 & 0,534 & 0,04 & 20 & 0,547 & 0,17 & 10 \\
\hline
\end{tabular}
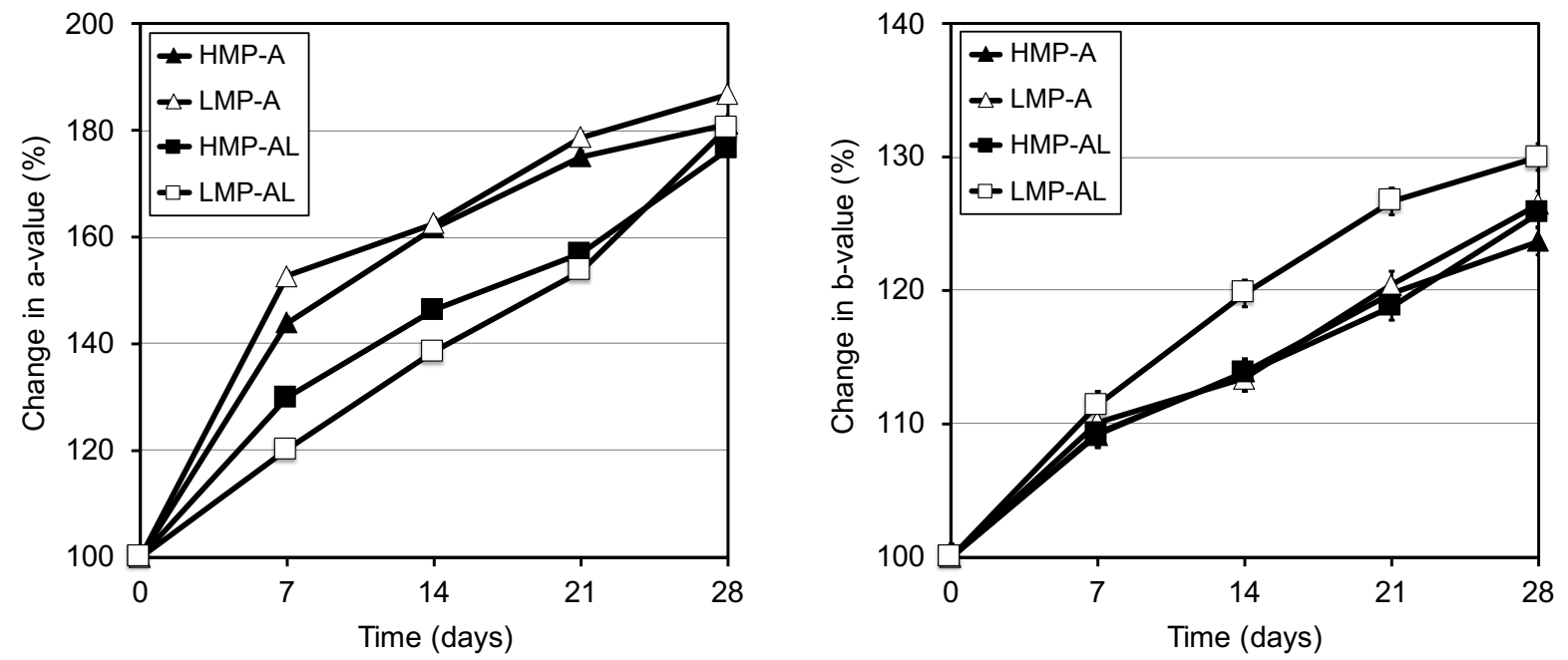

Figure 4: Increase of $a$ - and $b$-value during thermal degradation at $40 \%$ rh. HMP = high-methoxylated pectin, $L M P=$ low-methoxylated pectin, $-A=$ acidic modified $-A L=$ alkaline modified .

Colour formation occurred during storage at $40 \% \mathrm{rh}$ in pectin samples from both modifications (Fig. 4). Red colour formation was more pronounced in A-samples than in AL-samples during the first 21 days. However, after 28 days red colour formation of all samples was similar. Yellow colour formation was strongest for LMP-AL at the beginning, but differences vanished during the last seven days of storage. It might be assumed that red colour formation in the first 3 weeks mainly resulted 
from the decomposition of unsaturated uronides, which were formed by eliminative decarboxylation to a higher extent in A-pectins. Later on, decomposition of neutral sugars might have enhanced the colour formation, and this second effect would have been slightly more pronounced for the AL-pectin samples due to their higher content of neutral sugars $(5.1-6.8 \%$ in A- and $8.2-8.8 \%$ in AL-pectins).

In summary, thermolysis at $40 \%$ rh was observed, but the low moisture content restricted reactions requiring water (demethoxylation, cleavage of neutral sugars, backbone hydrolysis, Fig. 1). Less intense demethoxylation resulted in a lower number of free carboxyl groups, and hence depolymerisation by eliminative decarboxylation was also reduced. Demethoxylation and depolymerisation in AL-pectins were less pronounced than in the A-pectins. The difference between the two modified pectin types was confirmed also by the results of GPC (Fig. S1) as well as of DSC and DTG (Fig. S2), shown in the supplementary material.

\subsection{Comparison of degradation at $80 \%$ and $40 \%$ rh}

Aim of the present work was to achieve a better understanding of the depolymerisation mechanisms by comparing the results of storage at $40 \%$ rh with recent data from storage at $80 \%$ rh (EinhornStoll et al., 2019). Before starting a detailed analysis of the chemical degradation, a short examination of the alteration of material properties during storage provides an impression of the intensity of the pectin-water interactions.

\subsubsection{Alteration of the material properties during thermolysis}

The total particle surface (measured as BET-surface) is a suitable parameter for evaluation of the particle properties as well as of physical alteration of pectin powder particles during thermolysis. As shown in Fig. 5, the BET-surface of AL-pectin is generally larger than for A-pectin samples due to differences in particle size and form, which are clearly visible in the SEM-images (Fig. 6) and result from varying modification procedures, as described in detail recently (Einhorn-Stoll et al., 2019). A decrease of the BET-surface in a humid environment in general was explained as the consequence of swelling, softening and limited dissolution of the particle surface (Basu et al., 2013; Vasquez, Braganza, \& Coronella, 2011; Matveev et al., 2000), the outside layer of particles was smoothened and became sticky, pores were reduced or vanished, and some particles agglomerated. Accordingly, in the present study a reduction of the BET-surface during storage in the climate chamber was found in all pectin samples (Fig. 5, Table 1). Surface smoothing and, in particular, agglomeration was less pronounced at $40 \%$ compared to $80 \% \mathrm{rh}$, and it was more intensive in the small fibrous particles of the AL-pectin than in the large compact particles of A-pectin samples. 


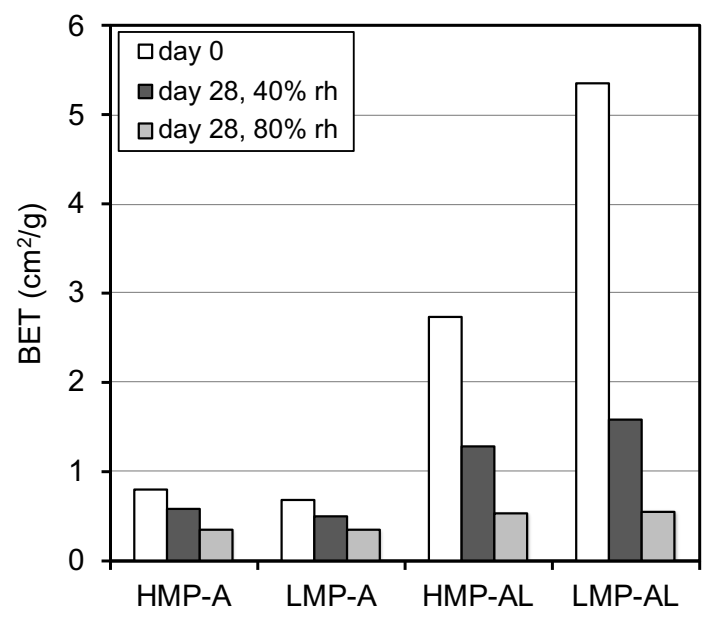

Figure 5: Alteration of BET-surface during thermal degradation of pectins at 40or 80\% relative humidity.
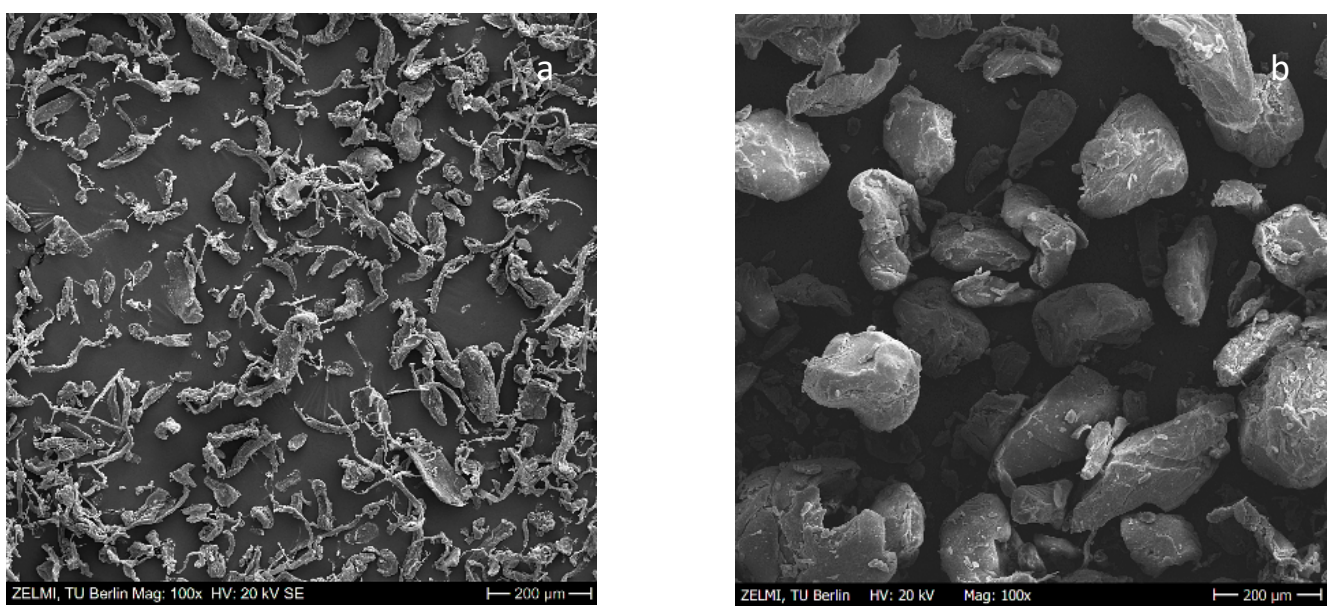

Figure 6: SEM-images of pectin particles prepared by alkaline (a) and acidic modification (b).

\subsubsection{Impact of relative humidity on pectin demethoxylation}

Demethoxylation during storage was generally lower at $40 \%$ than at $80 \%$ rh (Table 1, Fig. 7). This was expected, since the reaction depends on the moisture content. Thermal analysis confirmed these findings (Fig. 8). A shift of the DSC-curves to a lower temperature (earlier pyrolysis) is characteristic for pectin demethoxylation (Einhorn-Stoll, Kunzek, \& Dongowski, 2007), and this shift was less pronounced after storage at reduced rh. DSC curves revealed also another difference between pectin degradation at $40 \%$ and $80 \% \mathrm{rh}$. The height of an initial endothermic DSC-peak, observed only for acidic modified samples, decreased after storage. This peak represents an energy barrier at the beginning of pyrolysis and is ascribed to the energy that is required for loosening hydrogen bonds (Einhorn-Stoll \& Kunzek, 2009). The peak height is reduced, since some of the bonds were already cleaved during storage. This process depends on the presence of water, and therefore peak height reduction was more pronounced at $80 \%$ than at $40 \% \mathrm{rh}$. 


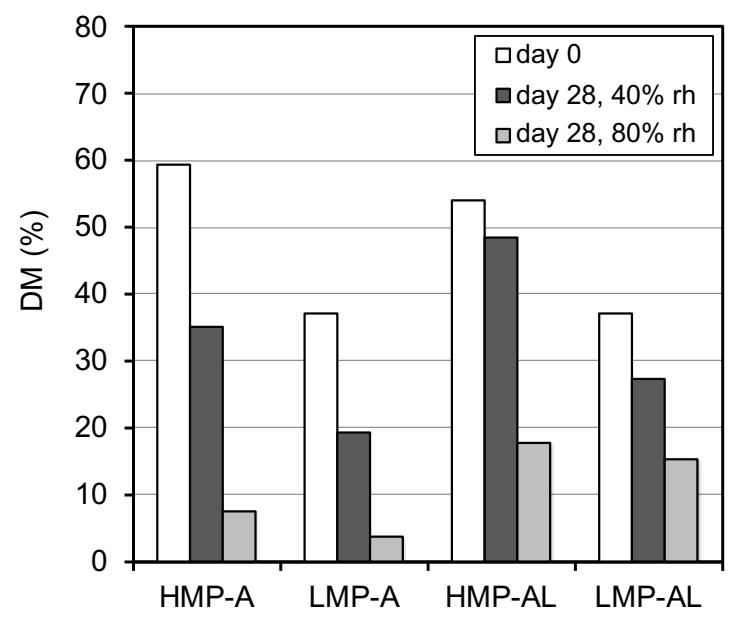

Figure 7: Alteration of DM during thermal degradation of pectins at 40 or $80 \%$ relative humidity.
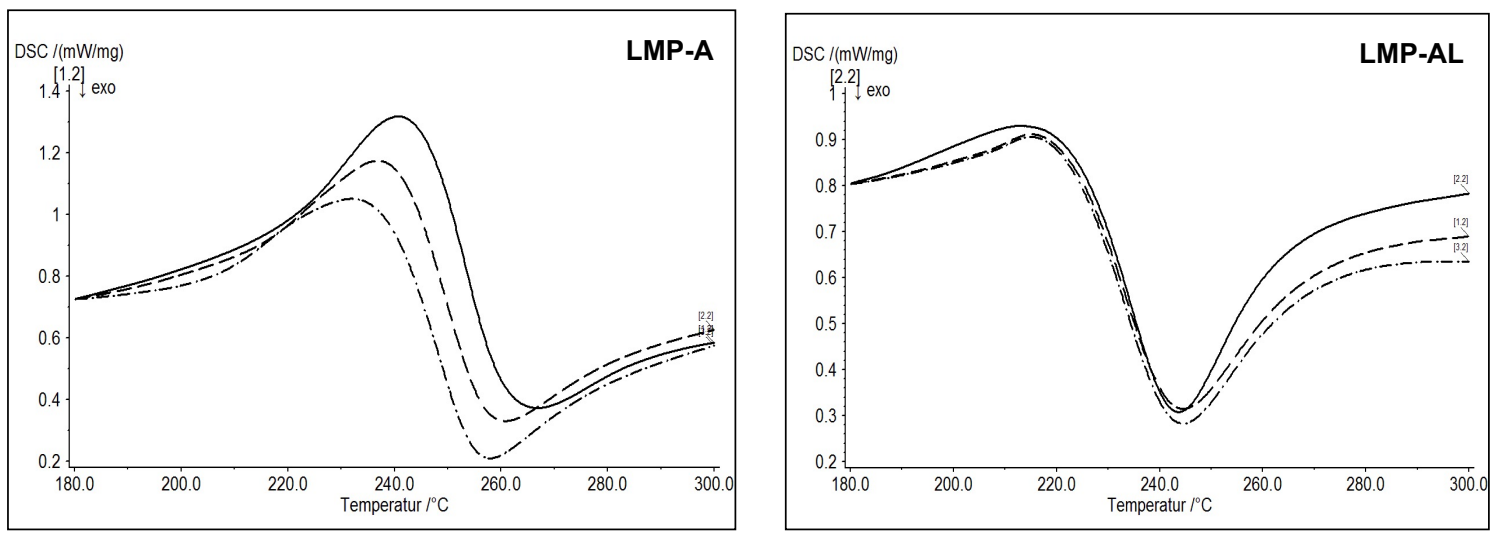

Figure 8: DSC-curves of modified and degraded pectins. - before storage at day o, --- after storage for 28 days at $40 \%$ humidity, --- after storage for 28 days at $80 \%$ humidity.

\subsubsection{Impact of relative humidity on pectin depolymerisation}

Depolymerisation was characterised using two different methods. Direct analysis via qualitative gel permeation chromatography (GPC, Fig. 9) shows the molecular weight (MW) distribution. Peaks of high MW (> $100 \mathrm{kDa}$ ), appearing by elution between 7 to $17 \mathrm{~min}$, shifted and / or shrunk as a result of depolymerisation. Peaks representing smaller molecules (MW about $0.3 \mathrm{kDa}$, peak maximum after 22 min elution time) were formed in A-pectin samples after storage at $80 \%$ but not at $40 \% \mathrm{rh}$. A similar alteration was, however, hardly detectable in stored AL-pectins. The second method is the determination of the intrinsic viscosity. This parameter (Table 1 ) is linked to the MW via the MarkHouwink equation, and thus indirectly provides information on the average MW of a sample (Anger \& Berth, 1986). Its determination is often used for routine analysis when comparing the molecular weight of different pectin samples (Protte, Balinger, Weiss, Löffler, \& Nöbel, 2019; Andersen et al., 2017; Migliori, Gabriele, Checchetti, \& Battipede, 2010; Dongowski, 1995). 

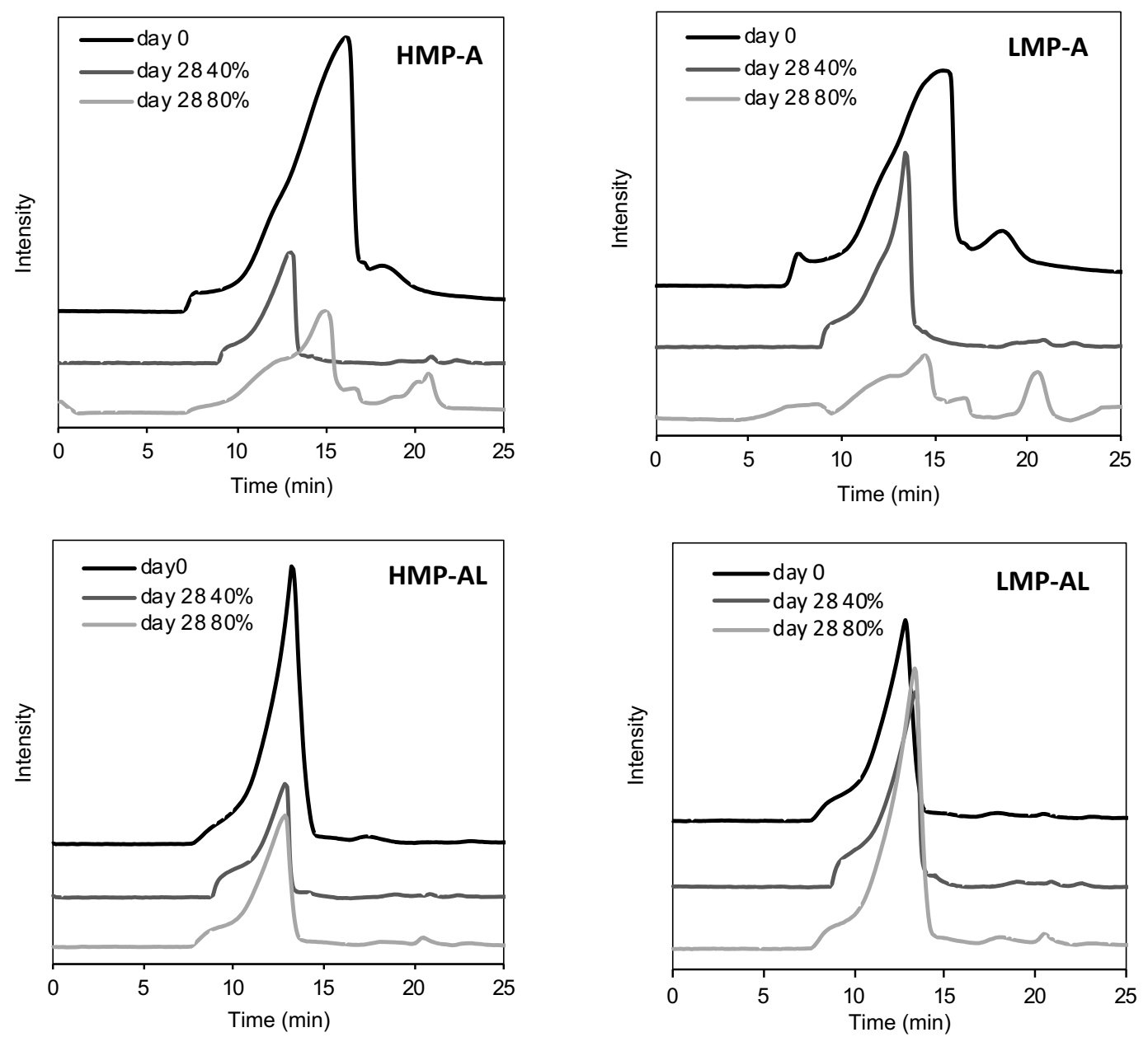

Figure 9: Alteration in GPC images during thermal degradation of pectins in a climate chamber at 400 r $80 \%$ relative humidity.

In the present work, relative humidity only had a low impact on the intrinsic viscosity of the pectin samples after storage. All values were of the same magnitude at both levels of rh (Table 1) and varied only about $5 \%$, which is within the analytical error of this method. A possible explanation for the different trends of intrinsic viscosity and GPC is the hydrodynamic volume in different solvents: Samples were dissolved in water for GPC but need to be dissolved in buffer for intrinsic viscosity measurement. It is known that the hydrodynamic volume of pectin molecules in buffer is lower than in water (Fishman, Chau, Kolpak, \& Brady, 2001; Deuel, Solms, \& Altermatt, 1953). Moreover, there is no linear correlation between the two methods in the range of high MW > $100 \mathrm{kDa}$ (Anger \& Berth, 1986). Hence, it seems that the intrinsic viscosity was dominated by larger molecules, and that the hydrodynamic volume of the oligomers with $\mathrm{MW}<1 \mathrm{kDa}$ in buffer was so small that their impact on the intrinsic viscosity was within the error of this method.

\subsubsection{Contribution of the different reaction types to depolymerisation during storage}

Depolymerisation of pectin during storage is not completely understood, and the role of water is more complex than it seems at first glance. Only one of the three relevant degradation reactions, backbone hydrolysis, requires water. The other two reactions, $\beta$-elimination and eliminative 
decarboxylation (Fig. 1) are only indirectly affected by the extent of the water-depending demethoxylation. A higher extent of demethoxylation at $80 \% \mathrm{rh}$ than at $40 \% \mathrm{rh}$ resulted in a higher number of newly formed free carboxyl groups, which supported eliminative decarboxylation and backbone hydrolysis. Thus, oligomers with $\mathrm{MW}<0.3 \mathrm{kDa}$, found in $\mathrm{GPC}$ at $80 \%$ but not at $40 \% \mathrm{rh}$, may result from these two reactions. Accordingly, a lower extent of demethoxylation at $40 \% \mathrm{rh}$ restricted these two reactions, but the remaining relative high number of methoxyl groups may favour $\beta$-elimination.

For the discussion of the complex interplay of reactions in thermolysis, the different extent of thermal degradation in acidic and alkaline demethoxylated pectin samples need to be considered. The two types of samples differ in their content of neutral sugars and sodium ions, which are higher in AL- than in A-pectins (see 3.1). Both factors reduce depolymerisation, as described above for degradation at $40 \% \mathrm{rh}$, as recently discussed in detail for storage at $80 \%$ rh (Einhorn-Stoll et al., 2019) and as shown for sodium ions in a parallel paper (Kastner et al., 2020). Another crucial factor is the number of methoxyl groups and free carboxyl groups in the pectin samples. As a result of the modification, the carboxyl groups (-COOH) were freely available in A-pectins but associated with sodium ions (-COONa) in AL-pectins (Einhorn-Stoll et al., 2019). Additional free carboxyl groups were formed in all pectin samples through demethoxylation during thermolysis. Their number was, however, higher in case of the A-pectins than in the AL-pectins. In total, the A-pectins contained more free carboxyl groups resulting from modification as well as from storage than AL-pectins, and the content was higher after storage at $80 \%$ than at $40 \% \mathrm{rh}$. These groups, adjacent to the glycosidic linkages to cleave, accelerated the depolymerisation by eliminative decarboxylation of acidic modified samples to a higher extent than that of the alkaline modified samples, and the impact was stronger at $80 \%$ than at $40 \% \mathrm{rh}$.

Another question in the context of pectin depolmerisation during storage is the occurrence of backbone hydrolysis. The reaction is nearly excluded for pectin by some authors (BeMiller \& Doyle, 1971; Timell, Enterman, Spencer, \& Solters, 1965), while other authors describe it as a typical reaction during thermal degradation in pectin solution and report a dependence of backbone hydrolysis intensity on the number of freely available carboxyl groups (Fraeye et al., 2007; Diaz et al., 2007; Krall \& McFeeters, 1998). The reaction is assumed to occur mainly in the rhamnogalacturonan region of the backbone between Rhamnose (Rha) and GalA molecules (van Buren, 1979), since Rha does not contain inhibiting groups at C-6. Moreover, Kravtchenko, Penci, Voragen and Pilnik (1993) found oligomer fragments of very low MW after acidic hydrolysis of pectin, which were predominantly cleaved from the ends of homogalacturonan segments of the backbone. It is however not clear, whether the reactions also occur during thermolysis in a lowmoisture environment like in the present study.

A discussion of pectin depolymerisation based on additional spectroscopy techniques, attenuated total reflectance Fourier-transform infrared (ATR-FTIR) spectroscopy and UV/VIS spectroscopy (at 
$235 \mathrm{~nm}, \mathrm{~A}_{235}$ ) was performed in order to help to understand the contribution of the individual depolymerisation reactions during storage. The signal region of the ATR-FTIR spectra below 2000 $\mathrm{cm}^{-1}$, in particular the fingerprint region below $1500 \mathrm{~cm}^{-1}$, provides broad information about chemical changes of the molecular structure during the depolymerisation process. For the interpretation of the degradation reactions during pectin storage, spectra of LMP and HMP after modification with different methods (but before storage) as well as after storage at different rh were compared as depicted in Fig. 10 and, in in a broader range of wavenumbers, in Figures $\mathrm{S}_{3}, \mathrm{~S}_{4}$ and $\mathrm{S}_{5}$ in the supplementary material. Figure $\mathrm{S}_{3}$ shows differences in the spectra due to acidic and alkaline demethoxylation, Figures $\mathrm{S}_{4}$ and $\mathrm{S}_{5}$ and, in particular, Fig. 10 are focused in detail on the alterations in the spectra due to thermolysis at different humidity.
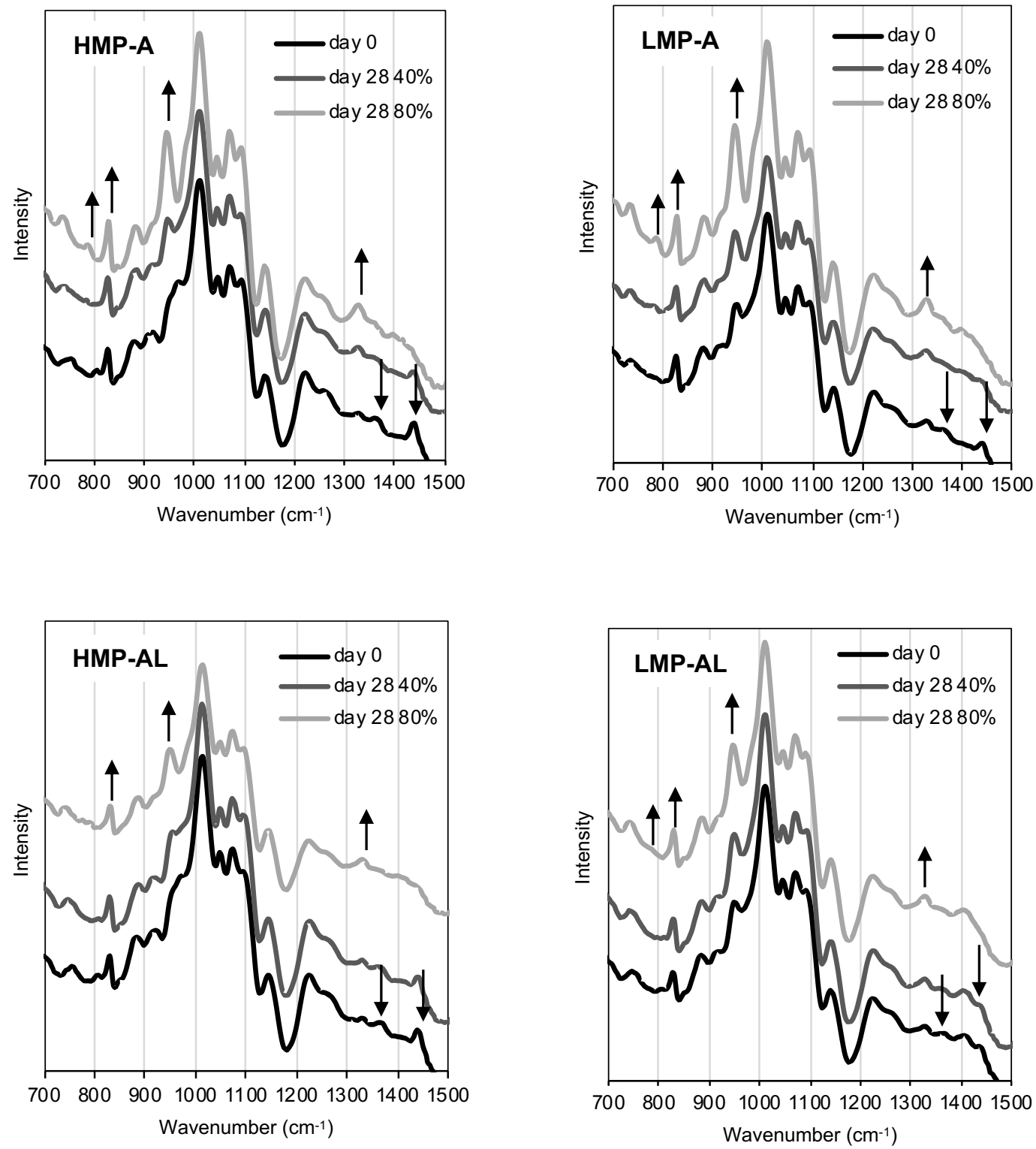

Figure 10: FT-IR images of the pectins before and after thermolysis in the climate chamber at 400 r $80 \%$ relative humidity.

Several publications describe characteristic IR bands and possible assignments to different elements of the pectin structure, including the degree of methoxylation as well as carbohydrate composition 
(Chylinska, Szymanska-Chargot, \& Zdunek, 2016; Fellah, Anjukandi, Waterland, \& Williams, 2009; Coimbra, Barros, Rutledge, \& Delgadillo, 1999; Chatjigakis et al., 1998). Table S2 in the supplementary material provides a summary of these references. Pectin structure is mainly characterised by stretch vibrations of the carbohydrate skeleton ( $\mathrm{C}-\mathrm{O}$ and $\mathrm{C}-\mathrm{OH}$ bonds) between 1200 and $900 \mathrm{~cm}^{-1}$ (Csanádi, Cserjési, Nemestóthy, \& Bélafi-Bakó, 2012; Synytsya, Copiková, Matějka, \& Machovič, 2003). According to Chylinska et al. (2016), GalA is represented by signals at 1015 up to $1100 \mathrm{~cm}^{-1}$ and rhamnogalacturonan I at $950 \mathrm{~cm}^{-1}$. Coimbra et al. (1998) reported signals at $1020-1150 \mathrm{~cm}^{-1}$ for GalA, at $1050 \mathrm{~cm}^{-1}$ for Arabinose (Ara) and at $945 \mathrm{~cm}^{-1}$ for Galactose (Gal), whereas a signal at $950 \mathrm{~cm}^{-1}$ was ascribed to galacturonic acid dimers (Engelsen, \& Norgaard, 1996), and was found also in pectates from LMP by Synytsya et al. (2003). Own measurements gave a signal for Rha at $975 \mathrm{~cm}^{-1}$.

Major changes in the tested pectin samples were observed at $950 \mathrm{~cm}^{-1}$, where the signal markedly increased during thermolysis. Prior to thermolysis, only a small shoulder was found in the spectra of the two HMP and a small separate signal in those of the two LMP. The signal at $1015 \mathrm{~cm}^{-1}$ increased, too, and formed a shoulder at about $975 \mathrm{~cm}^{-1}$. All these alterations were more pronounced at 80\% than at $40 \% \mathrm{rh}$ and were more intense in A-pectin than in AL-pectin samples (Figure 10). The alterations at 1015 and $1100 \mathrm{~cm}^{-1}$ were ascribed to free GalA and might be the result of any depolymerisation during storage, in particular at $80 \% \mathrm{rh}$. The increase in the signal at $950 \mathrm{~cm}^{-1}$ indicates an increase of GalA dimers. They were formed either from larger oligomers in the course of the depolymerisation or resulted from depolymerisation by backbone hydrolysis at the ends of the pectin molecule as postulated by Kravtchenko et al. (1993). Both reactions were more pronounced in A-pectin samples, due to their higher initial content of free carboxyl groups without sodium loading, and they were stronger at $80 \%$ than at $40 \%$ rh due to a higher additional number of free carboxyl groups formed by stronger demethoxylation. The shoulder formed at $975 \mathrm{~cm}^{-1}$ was ascribed to Rha (and partly Ara) and might result from a better detection of Rha after backbone hydrolysis in the rhamnogalacturonan region as described by van Buren (1979). This explanation is supported by a simultaneous increase in signal intensity of $1330 \mathrm{~cm}^{-1}$, which reflects ring vibration of saturated sugar rings. From the higher intensity of these alterations in the FT-IR spectra at $80 \%$ rh than at 40\% rh and in A-than in AL-pectins, it was concluded that backbone hydrolysis was possible, but mainly at higher rh and more prominent in A- than in AL-pectin samples.

In addition, the occurrence of a more pronounced depolymerisation through eliminative decarboxylation with formation of unsaturated uronides at elevated rh is supported by the stronger decrease of ester derived signals (1440 and $1362 \mathrm{~cm}^{-1}$ ) and simultaneous increase of $\mathrm{C}=\mathrm{C}$ stretch and deformation vibrations (1640, 830, $785 \mathrm{~cm}^{-1}$ ), as shown in Figure 10 and Figures $\mathrm{S}_{4}$ and $\mathrm{S} 5$, due to formation of unsaturated structures at $80 \% \mathrm{rh}$. These changes are most prominent in A-pectins at high rh and they are obvious when spectra of differently modified pectin samples (Figure S4) and after storage at different relative humidity were directly compared (Figure $\mathrm{S}_{5}$ ). Since the signals in 
FT-IR, as discussed above, show an overlay with different other bands not affected by thermolysis (Table S2), no specific individual wave number reflects pectin degradation. Nevertheless, the combination of the observed spectral changes clearly supports the formation of more unsaturated uronides by eliminative decarboxylation at higher rh. In addition, UV-absorption at $235 \mathrm{~nm}$ reflects the content of unsaturated galacturonides (uOGA) (Kravtchenko, Voragen, \& Pilnik, 1992), which are formed by depolymerisation via $\beta$-elimination and eliminative decarboxylation but not by backbone hydrolysis. In the present study, the increase of $A_{235}$ during storage (Table 1) was much lower at $40 \% \mathrm{rh}$ (9 to $52 \%$ ) than at $80 \%$ rh (34 to 128\%), and it was more pronounced for the Athan for the AL-pectin samples. This observation supports the indirect but strong impact of the water content on the extent of $\beta$-elimination and decarboxylation as discussed above. If a higher extent of backbone hydrolysis was the major reason for the more pronounced depolymerisation at higher rh, the amount of unsaturated uronides would have been nearly constant, and the alteration of $\mathrm{A}_{235}$ would have been similar at both rh.

Another question was to which extent eliminative decarboxylation or $\beta$-elimination account for pectin depolymerisation during storage. As explained above, a higher intensity of demethoxylation at $80 \%$ rh favoured eliminative decarboxylation. In contrast, a lower extent of demethoxylation at $40 \% \mathrm{rh}$ left a higher number of methoxyl groups after storage, which facilitate $\beta$-elimination. It might be expected, that the two reactions would compensate each other, and that the resulting formation of uOGA (measured as alteration of $\mathrm{A}_{235}$ ) would be nearly constant, independent on rh. In contrast, the increase of $\mathrm{A}_{235}$ (Table 1) was lower at $40 \% \mathrm{rh}$, and the total extent of the two reactions was not similar. This observation indicates that a more pronounced $\beta$-elimination at $40 \% \mathrm{rh}$ was not able to compensate the effect of a reduced eliminative decarboxylation. The results from UV absorption $\left(\mathrm{A}_{235}\right)$ were reflected in the reduced rate of browning during storage at lower rh (Table 1). Coloured red $(+a)$ and yellow $(+b)$ reaction products result mainly from the further decomposition of uOGA (formed by decarboxylation as well as $\beta$-elimination) as recently described by Bornik \& Kroh (2013) and Urbisch et al. (2018). During storage at lower rh, less uOGA were formed by depolymerisation and, as a consequence, their further decomposition was limited. In addition, the process was inhibited since it requires water, at least in the beginning or during intermediate steps.

In summary, it was found that the three depolymerisation reactions occurred parallel during pectin storage, and that their extent was determined by both, pectin molecular parameters resulting from different modification procedure as well as by the water supply during storage:

- Backbone hydrolysis was possible in dry pectins during storage, but only at $80 \% \mathrm{rh}$.

- $\beta$-elimination was particularly favoured in the beginning of storage but decreased with decreasing DM.

- Eliminative decarboxylation was the main depolymerisation reaction during storage. Any factor, that restricted this reaction, reduced the total extent of depolymerisation. 


\section{Conclusions}

Thermal degradation of pectin occurred even in a low moisture environment of $40 \% \mathrm{rh}$ with no measurable water uptake. Beside the chemical degradation, an alteration of the pectin material properties was found, though to a lower extent than at rh $80 \%$. The comparison of the degradation reaction intensity at $40 \%$ and $80 \%$ rh led to a better understanding of the complex depolymerisation mechanism during thermolysis and of the impact of the co-occuring demethoxylation. From the presented results it can be concluded, that backbone hydrolysis is generally possible during pectin storage, but requires a high environmental humidity. The reaction is supported by a high number of free carboxyl groups, resulting from modification as well as from demethoxylation. $\beta$-elimination is favoured in particular in high-methoxylated pectin and at the beginning of storage. In the course of degradation, its relevance decreases with decreasing DM. Depolymerisation via eliminative decarboxylation is the main depolymerisation reaction during storage. Similar to backbone hydrolysis, it is facilitated in case of a high number of free carboxyl groups. Any factor limiting eliminative decarboxylation, reduced the total depolymerisation during thermolysis. None of the other two reactions was able to compensate or replace it. Structural alterations during thermal degradation were not only affected by the number of free carboxyl groups in the pectin samples and by the water content, but also by the content of neutral sugars and sodium ions. These factors on the one hand reduce demethoxylation and depolymerisation, and on the other hand they determine the material properties of the pectin particles and affect the extent of their alteration during storage. 


\section{Acknowledgements}

The authors are grateful for the financial support of the Deutsche Forschungsgemeinschaft (DFGproject Nr. DR 806/4-1 "Structure-depending degradation reactions of pectins and their impact on non-enzymatic browning and technological functionality"). They also would like to thank Christina Eichenauer from the Institute of Chemistry of the TU Berlin for BET-surface measurement, Mario Harke from Julius Kühn-Institute for ATR-FTIR measurements, and Astrid Kliegel for pectin characterisation.

\section{CRediT authorship contribution statement}

Ulrike Einhorn-Stoll: Conceptualization, Methodology, Investigation, Formal analysis, Validation, Writing - original draft. Hanna Kastner: Methodology, Investigation, Validation, Visualization, Formal analysis, Writing - original draft. Alexandra Fatouros: Investigation, Methodology, Validation. Andrea Krähmer: Investigation, Validation, Writing - review \& editing, Visualization. Lothar W. Kroh: Funding acquisition. Stephan Drusch: Writing - review \& editing, Funding acquisition. 


\section{List of abbreviations}

$\mathrm{A}_{235}$

A-pectin Demethoxylated under acidic conditions

$-\mathrm{A}$

AL-pectin Demethoxylated under alkaline conditions

$-\mathrm{AL}$

Ara

BET

$\mathrm{CP}$

$\mathrm{DM}$

DSC

Gal

GalA

Glu

GPC

HMP

LMP

MW

NS

rh

Rha

SEM

$\mathrm{T}$

TG

X-ray

Xyl

$[\eta]$

Alkaline modified

Arabinose

Commercial pectin

Degree of methoxylation

Differential scanning calorimetry

Galactose

Galacturonic acid

Glucose

Gel permeation chromatography

High-methoxylated pectin

Low-methoxylated pectin

Molecular weight

Neutral sugars

Relative humidity

Rhamnose

Scanning electron microscopy

Temperature

Thermogravimetry

Structure analysis

Xylose

Intrinsic viscosity

Brunauer-Emmett-Teller (method for calculating the surface of powders) 


\section{References}

Andersen, N. M., Cognet, T., Santacoloma, P. A., Larsen, J., Armagan, I., Larsen, F. H., ... Huusom, J. K. (2017). Dynamic modelling of pectin extraction describing yield and functional $\begin{array}{lllll}\text { characteristics. } & \text { Journal } & \text { Food } & \text { Engineering, } & \text { 192, }\end{array}$ https://doi.org/10.1016/j.jfoodeng.2016.08.006

Anger, H., \& Berth, G. (1986). Gel permeation chromatography and the Mark-Houwink relation for pectins with different degrees of esterification. Carbohydrate Polymers, 6, 193-202. https://doi.org/10.1016/0144-8617(86)90019-6

Axelos, M. A. V., \& Branger, M. (1993). The effect of the degree of esterification on the thermal stability and chain conformation of pectins. Food Hydrocolloids, 7(2), 91-102. https://doi.org/10.1016/So268-005X(09)80161-6

Basu, S., Shivhare, U. S., \& Muley, S. (2013). Moisture adsorption isotherms and glass transition temperature of pectin. Journal of Food Science and Technology, 50, 585-589. https://doi.org/10.1007/s13197-011-0327-y

Bäuerle, G., Otterbach, G., Gierschner, K., \& Baumann, G. (1977). Bestimmung des Polyuronidgehalts und des Veresterungsgrades von Handelspektinpräparaten. Deutsche Lebensmittel-Rundschau, 73(9), 281-286.

BeMiller, J. N., \& Doyle, E. R. (1971). Acid-catalyzed hydrolysis of alkyl-a-D-glucopyranosides. Carbohydrate Research, 20, 23-30.

BeMiller, J. N., \& Kumari, G. V. (1972). beta-Elimination in uronic acids: Evidence for an ElcB Mechanism. Carbohydrate Polymers, 25, 419-428.

Blumenkrantz, N, Asboe-Hansen, G. (1973). New method for quantitative determination of uronic acids. Anal. Chem., 54, 484-489.

Bornik, M., \& Kroh, L. W. (2013). D-Galacturonic acid as a highly reactive compound in nonenzymatic browning. 1. Formation of browning active degradation products. Retrieved from http://pubs.acs.org/doi/pdf/10.1021/jf303855s

Chylinska, M., Szymanska-Chargot, M., \& Zdunek, A. (2016). FT-IR and FT-Raman characterization of non-cellulosic polysaccharides fractions isolated from plant cell wall. Carbohydrate Polymers, 154, 48-54. https://doi.org/10.1016/j.carbpol.2016.07.121

Coimbra, M. A., Barros, A., Barros, M., Rutledge, D., \& Delgadillo, I. (1998). Multivariate analysis of uronic acid and neutral sugars in whole pectic samples by FT-IR spectroscopy. Carbohydrate Polymers, 37, 241-248.

Coimbra, M. A., Barros, A., Rutledge, D. N., \& Delgadillo, I. (1999). FTIR spectroscopy as a tool for the analysis of olive pulp cell-wall polysaccharide extracts. Carbohydrate Research, 317(1-4), 
145-154. https://doi.org/10.1016/Sooo8-6215(99)ooo71-3

Csanádi, Z., Cserjési, P., Nemestóthy, N., \& Bélafi-Bakó, K. (2012). Characterization of pectins from press residues of berries by FT-IR spectroscopy. Acta Alimentaria, 41(1), 94-99. https://doi.org/10.1556/AAlim.41.2012.1.11

Diaz, J. V., Anthon, G. E., \& Barrett, D. M. (2007). Nonenzymatic degradation of citrus pectin and pectate during prolonged heating: Effects of $\mathrm{pH}$, temperature, and degree of methyl esterification. Journal of Agricultural and Food Chemistry, 55, 5131-5136. https://doi.org/10.1021/jfo701483

Dongowski, G. (1995). Influence of pectin structure on the interaction with bile acids under in vitro conditions. Zeitschrift f??R Lebensmittel-Untersuchung Und -Forschung, 201, 390-398. https://doi.org/10.1007/BFo1192740

Einhorn-Stoll, U., Kastner, H., \& Drusch, S. (2014). Thermally induced degradation of citrus pectins during storage - Alterations in molecular structure, colour and thermal analysis. Food Hydrocolloids, 35, 565-575. https://doi.org/10.1016/j.foodhyd.2013.07.020

Einhorn-Stoll, U., Kastner, H., Urbisch, A., Kroh, L. W., \& Drusch, S. (2019). Thermal degradation of citrus pectin in low-moisture environment - Influence of acidic and alkaline pre-treatment. Food Hydrocolloids, 86, 104-115. https://doi.org/10.1016/j.foodhyd.2018.02.030

Einhorn-Stoll, U., Prinz, C., \& Drusch, S. (2014). Influence of storage on water binding of pectins: Determination by DSC. In Peter .A. Williams \& G. O. Phillips (Eds.), Gums and Stabilisers for the Food Industry 17 (pp. 147-154). RCS Publishing.

Einhorn-Stoll, U., Benthin, A., Zimathies, A., Görke, O., \& Drusch, S. (2015). Pectin-water interactions: Comparison of different analytical methods and influence of storage. Food Hydrocolloids, 43, 577-583. https://doi.org/10.1016/j.foodhyd.2014.07.013

Einhorn-Stoll, U., Kastner, H., Urbisch, A., Kroh, L. W., \& Drusch, S. (2019). Food Hydrocolloids Thermal degradation of citrus pectin in low-moisture environment - In fl uence of acidic and alkaline pre-treatment. Food Hydrocolloids, $\quad 86, \quad$ 104-115. https://doi.org/10.1016/j.foodhyd.2018.02.030

Einhorn-Stoll, U., \& Kunzek, H. (2009). The influence of the storage conditions heat and humidity on conformation, state transitions and degradation behaviour of dried pectins. Food Hydrocolloids, 23, 856-866. https://doi.org/10.1016/j.foodhyd.2008.05.001

Einhorn-Stoll, U., Kunzek, H., \& Dongowski, G. (2007). Thermal analysis of chemically and mechanically modified pectins. Food Hydrocolloids, 21, 1101-1112. https://doi.org/10.1016/j.foodhyd.2006.08.004

Endress, H. U. (2011). Pectins : Production, properties and applications. In P. A. Williams (Ed.), Renewable resources for functional polymers and biomaterials (pp. 210-267). RSC Polymer 
Chemistry Series.

Engelsen, S. B., \& Norgaard, L. (1996). Comparative vibrational spectroscopy for determination of quality parameters in amidated pectinas evaluated by chemometrics. Carbohydrate Polymers, $30,9-24$.

Fellah, A., Anjukandi, P., Waterland, M. R., \& Williams, M. A. K. (2009). Determining the degree of methylesterification of pectin by ATR/FT-IR: Methodology optimisation and comparison with theoretical calculations. Carbohydrate Polymers, $\quad 78(4), \quad 847-853$. https://doi.org/10.1016/j.carbpol.2009.07.003

Fishman, M. L., Chau, H. K., Kolpak, F., \& Brady, J. (2001). Solvent effects on the molecular properties of pectins. Journal of Agricultural and Food Chemistry, 49, 4494-4501. https://doi.org/10.1039/c3cc46961a

Fraeye, I., De Roeck, A., Duvetter, T., Verlent, I., Hendrickx, M., \& Van Loey, A. (2007). Influence of pectin properties and processing conditions on thermal pectin degradation. Food Chemistry, 105, 555-563. https://doi.org/10.1016/j.foodchem.2007.04.009

Kakuráková, M., Capek, P., Sasinkova, V., Wellner, N., Ebringerova, A., \& Kac, M. (2000). FT-IR study of plant cell wall model compounds: Pectic polysaccharides and hemicelluloses. Carbohydrate Polymers, 43, 195-203.

Kastner, H., Einhorn-Stoll, U., \& Drusch, S. (2019). Influence of enzymatic and acidic demethoxylation on structure formation in sugar containing citrus pectin gels. Food Hydrocolloids, 89, 207-215. https://doi.org/10.1016/j.foodhyd.2018.10.031

Kastner, H., Einhorn-Stoll, U., Fatouros, A., \& Drusch, S. (2020). Impact of sodium ions on material properties, gelation and storage stability of citrus pectin. Food Hydrocolloids, 104(February), 105750. https://doi.org/10.1016/j.foodhyd.2020.105750

Keijbets, M. J. H., \& Pilnik, W. (1974). ß-elimination of pectin in the presence of anions and cations. Carbohydrate Research, 33, 359-362.

Krall, S. M., \& McFeeters, R. F. (1998). Pectin Hydrolysis: Effect of temperature, degree of methylation, $\mathrm{pH}$, and calcium on hydrolysis rates. Journal of Agricultural and Food Chemistry, 46(1985), 1311-1315. https://doi.org/10.1021/jf970473y

Kravtchenko, T. P., Arnould, I., Voragen, a. G. J., \& Pilnik, W. (1992). Improvement of the selective depolymerization of pectic substances by chemical $\beta$-elimination in aqueous solution. Carbohydrate Polymers, 19, 237-242. https://doi.org/10.1016/0144-8617(92)90075-2

Kravtchenko, T. P., Penci, M., Voragen, A. G. J., \& Pilnik, W. (1993). Enzymic and chemical degradation of some industrial pectins. Carbohydrate Polymers, 2O, 195-205. https://doi.org/10.1016/0144-8617(93)90151-S 
Kravtchenko, T. P., Voragen, A. G. J., \& Pilnik, W. (1992). Analytical comparison of three industrial pectin preparations. Carbohydrate Polymers, 18, 17-25. https://doi.org/10.1016/01448617(92)90183-Q

Matveev, Y. I., Grinberg, V. Y., \& Tolstoguzov, V. B. (2000). The plasticizing effect of water on proteins, polysaccharides and their mixtures. Glassy state of biopolymers, food and seeds. Food Hydrocolloids, 14, 425-437. https://doi.org/10.1016/So268-005X(oo)ooo20-5

Migliori, M., Gabriele, D., Checchetti, A., \& Battipede, B. (2010). Compatibility analysis of pectin at different esterification degree from intrinsic viscosity data of diluted ternary solutions. Reactive $\quad$ and $\quad$ Functional 863-867. https://doi.org/10.1016/j.reactfunctpolym.2010.07.011

Padival, R.A., Ranganna, S., Manjrekar, S. P. (1981). Stability of pectins during storage. Journal of Food Technology, 16, 367-378.

Protte, K., Balinger, F., Weiss, J., Löffler, R., \& Nöbel, S. (2019). Establishing the biopolymer ratio of whey protein-pectin complexes before and after thermal stabilisation. Food Hydrocolloids, 89(July 2018), 554-562. https://doi.org/10.1016/j.foodhyd.2018.11.015

Renard, C. M. G. C., \& Thibault, J. F. (1996). Degradation of pectins in alkaline conditions: Kinetics of demethylation. Carbohydrate Research, 286, 139-150. https://doi.org/10.1016/ooo86215(96)00056-0

Rolin, C., Chrestensen, L. B., Hansen, K. M., Staunstrup, J., \& Sørensen, S. (2010). Tailoring pectin with specific shape, composition and esterification pattern. In P. A. Williams \& G. O. Phillips (Eds.), Gums and Stabilisers for the Food Industry 15 (pp. 13-25). Cambridge: RCS Publishing.

Rolin, C.. (2002). Commercial pectin preparations. In J. P. Seymor, G.B., Knox (Ed.), Pectins and their manipulations (pp. 221-241). Boca Raton: CRC.

Sajjaanantakul, T., Van Buren, J. P., \& Downing, D. L. (1993). Effect of cations on heat degradation of chelator-soluble carrot pectin. Carbohydrate Polymers, 20, 207-214. https://doi.org/10.1016/0144-8617(93)90152-T

Synytsya, A., Copiková, J., Matějka, P., \& Machovič, V. (2003). Fourier transform Raman and infrared spectroscopy of pectins. Carbohydrate Polymers, 54, 97-106. https://doi.org/10.1016/So144-8617(03)00158-9

Timell, T. E., Enterman, W., Spencer, F., \& Solters, E. J. (1965). The acid hydrolysis of glycosides. II. Effect of substituents at C-5. Canadian Journal of Chemistry, 43(9), 2296-2304. https://doi.org/10.1016/Sooo8-6215(oo)82576-8

Urbisch, A., Einhorn-Stoll, U., Kastner, H., Drusch, S., \& Kroh, L. W. (2018). Formation of Phenolic Compounds from D - Galacturonic Acid, 2-8. https://doi.org/10.1021/acs.jafc.8bo4158 
Van Buren, J. P. (1979). The Chemistry of texture in fruites and vegetables. Journal of Texture Studies, 1O(1), 1-23. https://doi.org/10.1111/j.1745-4603.1979.tbo1305.x

Vasquez, V. R., Braganza, A., \& Coronella, C. J. (2011). Molecular thermodynamics modeling of equilibrium moisture in foods. Journal of Food Engineering, 103(1), 103-114. https://doi.org/10.1016/j.jfoodeng.2010.10.005

Wegener, S., Kaufmann, M., \& Kroh, L. W. (2017). Influence of L-pyroglutamic acid on the color formation process of non-enzymatic browning reactions. Food Chemistry, 232, 450-454. https://doi.org/10.1016/j.foodchem.2017.04.046 


\section{Supplementary material}

\section{Degradation at $40 \% \mathrm{rh}$}

Storage at $60^{\circ} \mathrm{C}$ and $40 \%$ rh causes thermolysis of pectin all tested pectin samples. The course of the degradation process is shown in Table S1.

Table S1: Thermolysis of pectin samples at $40 \% \mathrm{rh}$

\begin{tabular}{cccccccccc}
\hline $\begin{array}{l}\text { Sample / } \\
\begin{array}{l}\text { Degradation } \\
\text { time }\end{array}\end{array}$ & $\begin{array}{c}\text { DM } \\
{[\%]}\end{array}$ & $\begin{array}{c}\text { IV } \\
{\left[\mathrm{cm}^{3} / \mathrm{g}\right]}\end{array}$ & $\mathrm{a}$ & $\mathrm{b}$ & $\begin{array}{l}\text { Sample } / \\
\text { Degradation } \\
\text { time }\end{array}$ & $\begin{array}{c}\text { DM } \\
{[\%]}\end{array}$ & $\begin{array}{c}\text { IV } \\
{\left[\mathrm{cm}^{3} / \mathrm{g}\right]}\end{array}$ & $\mathrm{a}$ & $\mathrm{b}$ \\
\hline HMP-A & 59.4 & 599 & 1.47 & 14.01 & HMP-AL & 54.1 & 575 & 1.03 & 11.38 \\
$7 \mathrm{~d}$ & 52.8 & 300 & 2.12 & 15.30 & $7 \mathrm{~d}$ & 54.1 & 435 & 1.34 & 12.43 \\
$14 \mathrm{~d}$ & 44.1 & 193 & 2.38 & 15.96 & $14 \mathrm{~d}$ & 49.8 & 351 & 1.51 & 12.95 \\
$21 \mathrm{~d}$ & 40.1 & 152 & 2.58 & 16.78 & $21 \mathrm{~d}$ & 48.6 & 305 & 1.62 & 13.52 \\
$28 \mathrm{~d}$ & 35.0 & 124 & 2.66 & 17.33 & $28 \mathrm{~d}$ & 48.5 & 249 & 1.82 & 14.32 \\
\hline LMP-A & 37.2 & 549 & 1.81 & 15.08 & LMP-AL & 37.2 & 465 & 1.22 & 11.49 \\
$7 \mathrm{~d}$ & 27.7 & 231 & 2.76 & 16.61 & $7 \mathrm{~d}$ & 31.7 & 339 & 1.46 & 12.80 \\
$14 \mathrm{~d}$ & 24.2 & 158 & 2.94 & 17.10 & $14 \mathrm{~d}$ & 30.8 & 283 & 1.69 & 13.77 \\
$21 \mathrm{~d}$ & 22.6 & 131 & 3.24 & 18.15 & $21 \mathrm{~d}$ & 29.0 & 249 & 1.87 & 14.56 \\
$28 \mathrm{~d}$ & 19.4 & 111 & 3.38 & 19.08 & $28 \mathrm{~d}$ & 27.2 & 215 & 2.20 & 14.94 \\
\hline
\end{tabular}

The GPC-images (Fig. S1) support the results of alteration of intrinsic viscosity during storage, which was stronger for the acidic than for the alkaline demethoxylated samples. In case of LMP-A, the biggest molecules (elution time about $8 \mathrm{~min}$ ) of the modified sample were cleaved and the resulting shoulder (elution time about $10 \mathrm{~min}$ ) decreased in the last two weeks. The peak of the smallest molecules (elution time about $18 \mathrm{~min}$ ) vanished by their rapid degradation within 14 days, producing browning unsaturated uronides. For the LMP-AL, the MW-distribution of the modified sample was more homogenous than in case of LMP-A due to stronger depolymerisation already in the course of the alkaline modification. The alteration in GPC of LMP-AL during storage was less intensive than in case of LMP-A, as was found also by the alteration of intrinsic viscosity. 

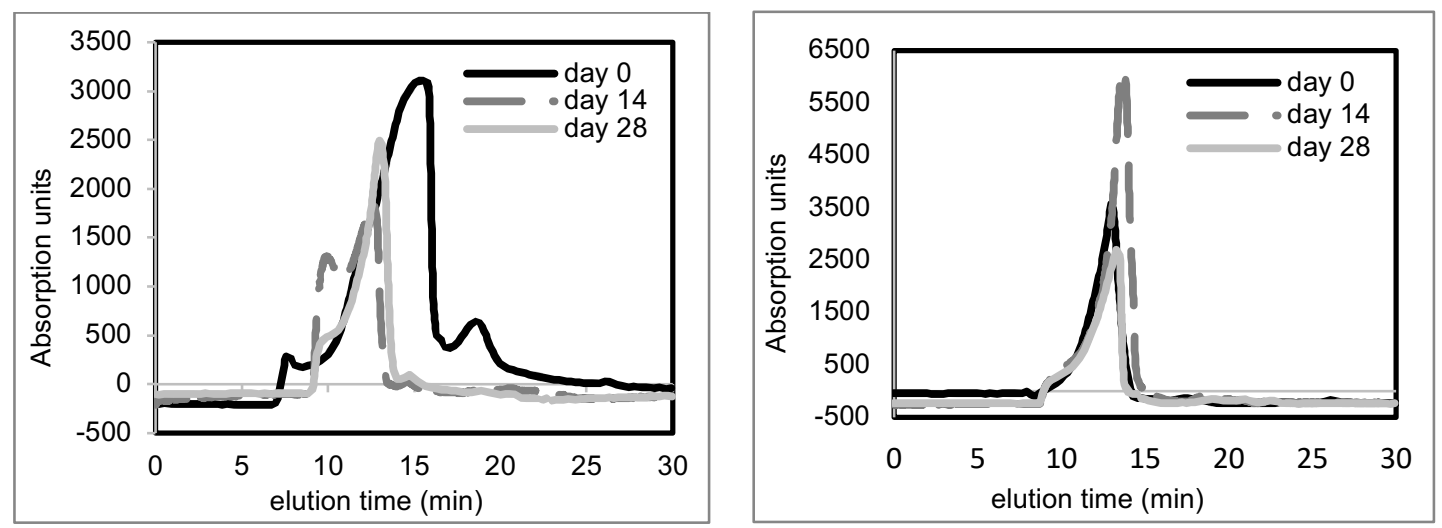

Fig. S1: Change in GPC-images by degradation of LMP-A (left) and LMP-AL (right) during storage at $60^{\circ} \mathrm{C}$ and $40 \%$ rh.

The thermolysis of the pectin is well reflected in the shift of the DSC-peak to the left (Fig. S2). The pyrolysis process started earlier with increasing sample degradation. This results from decreasing DM as well as MW (unpublished data) and was found also in our previous works. The decrease of the endothermic starting peak, reflecting a compact structure fixed by hydrogen bonds, was caused by loosening of some of these bonds already during storage. The shift of the DSC-peak during thermolysis corresponds to a decrease of the Onset-temperature of the DTG-peaks found for all tested samples. The impact on the acidic modified samples was stronger than that on the alkaline modified, confirming the different extent of change in DM and MW for the two pectin types as discussed above.
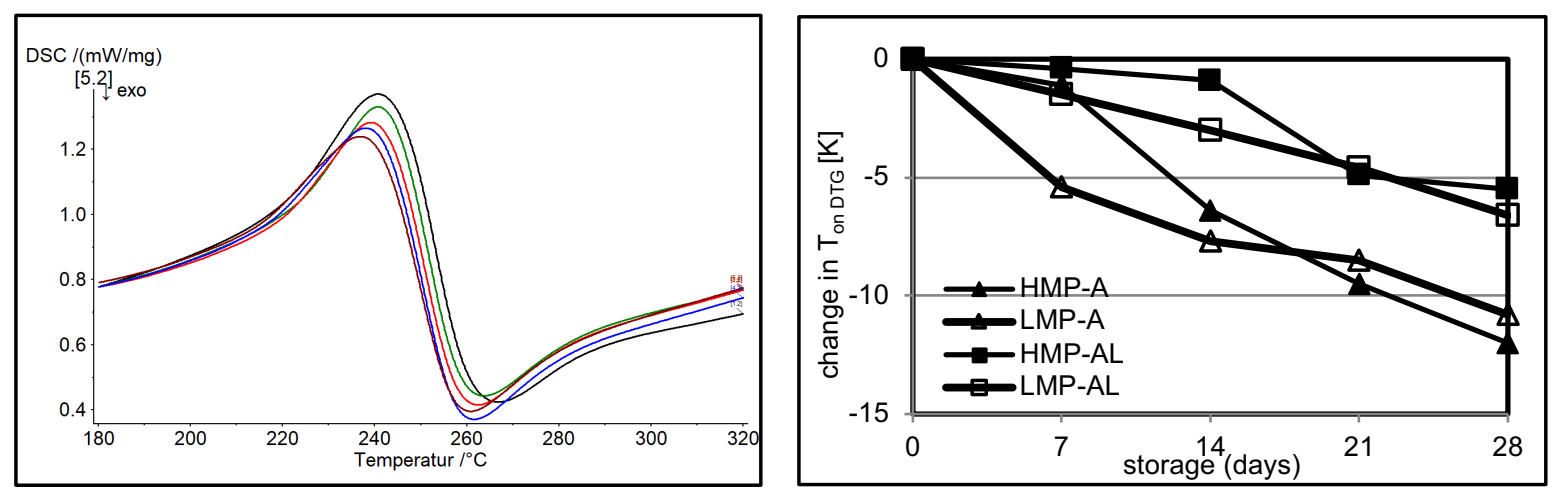

Fig. S2: Alterations in DSC and DTG during thermolysis. Left: Shift of DSC-curve and reduction of the endothermic $D T G$-peak at the start of pyrolysis of modified (black) and degraded (colored green $\rightarrow$ red $\rightarrow$ blue $\rightarrow$ brown) LMP-A in the course of storage. Right: Change of the extrapolated onset temperature of the DTG-peak.

\section{FT-IR investigation of pectin}

The fingerprint region of pectin in the ATR-FTIR spectra $\left(1800-700 \mathrm{~cm}^{-1}\right)$ provides information about chemical alteration of the molecular structure by demethoxylation prior to and by depolymerisation during storage. Several references assign characteristic IR bands to different pectin structures, including degree of methoxylation as well as carbohydrate composition (Chylinska, Szymanska-Chargot, \& Zdunek, 2016; Fellah, Anjukandi, Waterland, \& Williams, 2009; Coimbra, Barros, Rutledge, \& Delgadillo, 1999; Chatjigakis et al., 1998). A brief summary about 
band assignment gives Table S2.

Table S2: Characteristic ATR-FTIR absorption signals and corresponding band assignment

\begin{tabular}{|c|c|c|}
\hline$v\left(\mathrm{~cm}^{-1}\right)$ & assignment & structure \\
\hline 1732 & $\begin{array}{l}\vee \mathrm{ROC}=\mathrm{O} \\
\vee \mathrm{HOC}=\mathrm{O}\end{array}$ & organic acid methylester, free carboxyl group \\
\hline $1620-1645$ & $\mathrm{HC}=\mathrm{CH}$ cis $v_{\mathrm{C}=\mathrm{C}}$ & symmetric stretch vibration of cis-configurated $\mathrm{C}=\mathrm{C}$ \\
\hline $1630-1604$ & $v_{\mathrm{AS}} \mathrm{OC}-\mathrm{O}^{-} \mathrm{Na}^{+}$ & organic acid sodium salt (after AL treatment) \\
\hline 1440 & $\delta_{\mathrm{AS}} \mathrm{OCO}-\mathrm{CH}_{3}$ & organic acid methylester \\
\hline 1410 & $v_{\mathrm{s}} \mathrm{COO}^{-} \mathrm{Na}^{+}$ & organic acid sodium salt \\
\hline 1362 & $\delta_{\mathrm{S}} \mathrm{OCO}-\mathrm{CH}_{3}$ & organic acid methylester \\
\hline 1330 & $\gamma$ Ring & carbohydrate ring system \\
\hline 1142 & $\mathrm{C}-\mathrm{O}-\mathrm{C}$ & uronic acid, galacturonic acid (GalA), glycosidic linkage \\
\hline 1094 & $\mathrm{C}-\mathrm{O}-\mathrm{C}, \mathrm{C}-\mathrm{OH}$ & uronic acid, galacturonic acid (GalA) \\
\hline 1072 & $\mathrm{C}-\mathrm{O}-\mathrm{C}, \mathrm{C}-\mathrm{OH}$ & carbohydrate skeletal structure \\
\hline 1048 & $\mathrm{C}-\mathrm{O}-\mathrm{C}, \mathrm{C}-\mathrm{OH}$ & arabinose \\
\hline 1013 & $\mathrm{C}-\mathrm{O}-\mathrm{C}, \mathrm{C}-\mathrm{OH}$ & uronic acid, galacturonic acid (GalA) \\
\hline 975 & $\mathrm{C}-\mathrm{O}-\mathrm{C}, \mathrm{C}-\mathrm{OH}$ & arabinose, rhamnose \\
\hline 950 & $\mathrm{C}-\mathrm{O}-\mathrm{C}, \mathrm{C}-\mathrm{OH}$ & galacturonic acid (GalA), galactose, rhamnose \\
\hline 887 & $\mathrm{CH}-\mathrm{O}-\mathrm{CH}$ & ether \\
\hline 830 & $\gamma \mathrm{HC}=\mathrm{CH}$ cis & $\begin{array}{l}\text { conjugation with } \mathrm{C}=\mathrm{O} \text {, reducing and unsaturated uronoides } \mathrm{A}^{1} \text {, } \\
\text { overlay with glycosodic } 6 \text {-ring structure }\end{array}$ \\
\hline 785 & $\gamma \mathrm{HC}=\mathrm{CH}$ cis & reducing and unsaturated uronoides $\mathrm{A}^{1}$ and $\mathrm{B}^{2}$ \\
\hline
\end{tabular}

Considering the references, differences in the modified pectin samples before storage are confirmed by ATR-FTIR by characteristic absorptions patterns as shown in detail in the supplementary material (Table S2, Fig. S3-S5). 


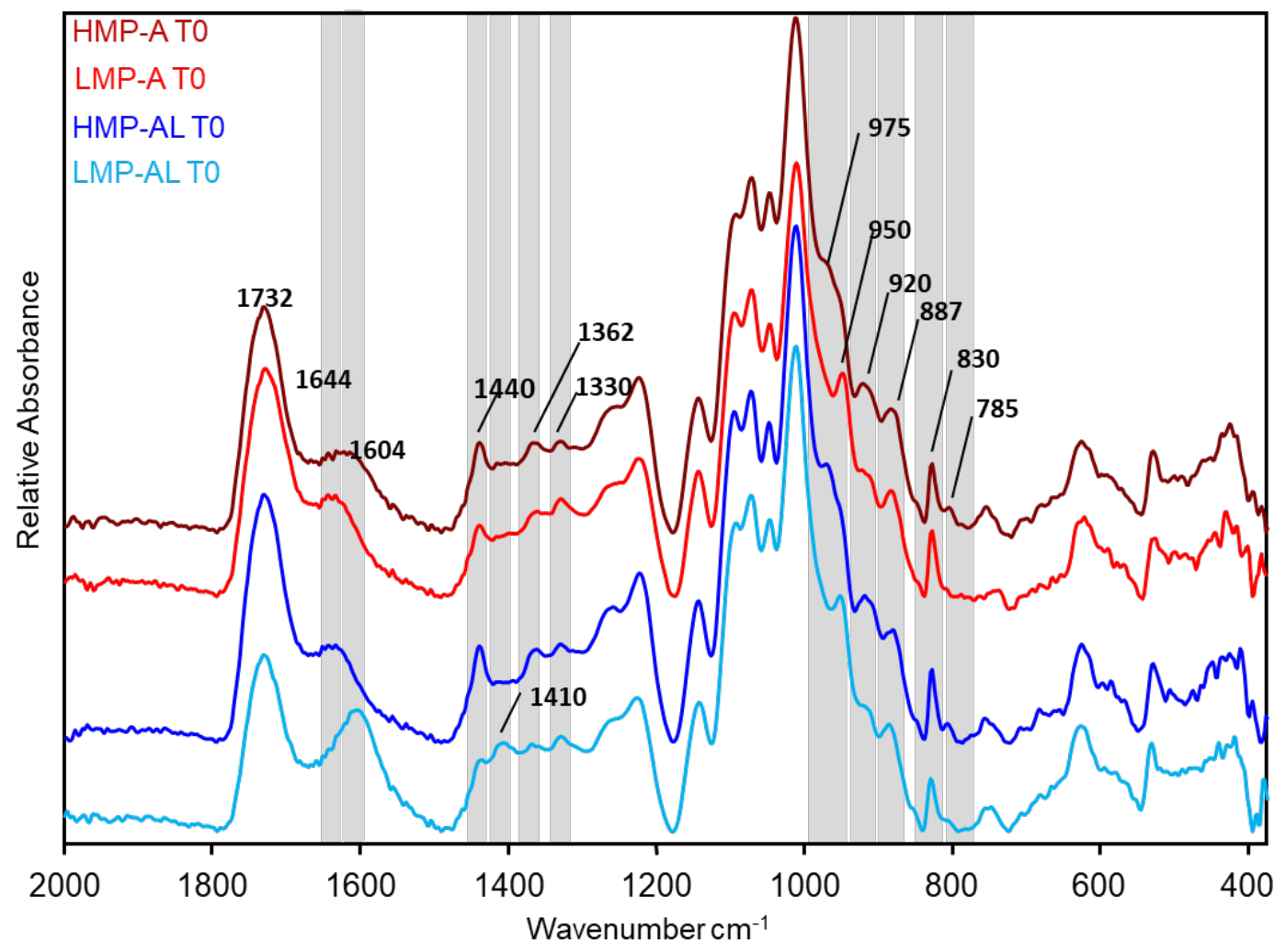

Fig. S3: FT-IR spectra of pectin samples after modification

As shown in Figure S3, spectra of HMP pectin show more intense ester derived bands $\left(1732 \mathrm{~cm}^{-1}\right.$, 1440 and $1362 \mathrm{~cm}^{-1}$ ) compared to LMP spectra. Additionally, HMP shows a signal shoulder at 975 $\mathrm{cm}^{-1}$ ascribed to rhamnose and arabinose, whereas the signal derived from GalA around $950 \mathrm{~cm}^{-1}$ is more pronounced in LMP samples. Furthermore, alkaline modification (AL) can be differentiated from acidic (A) one based on sodium carboxylate signals at around 1630-1604 and $1410 \mathrm{~cm}^{-1}$, respectively, which are more prominent in spectra of AL-pectin compared to A-pectin (Table S2). In contrast, acidic modification resulted in free protonated carboxyl groups showing a broad band around 1730 (overlay with $\mathrm{ROC}=\mathrm{O}$ ester) due to the stretch vibration of $\mathrm{HOC}=\mathrm{O}$.

The comparison of the spectra before and after storage (Fig. S4) illustrates the differences due to thermal degradation in more detail than Fig. 10. They were more pronounce for acidic than for alkaline modified pectins.

The impact of the water supply on thermolysis is underlined in detail by Figure $\mathrm{S}_{5}$. The alterations were stronger at rh $80 \%$ than at $40 \%$. 


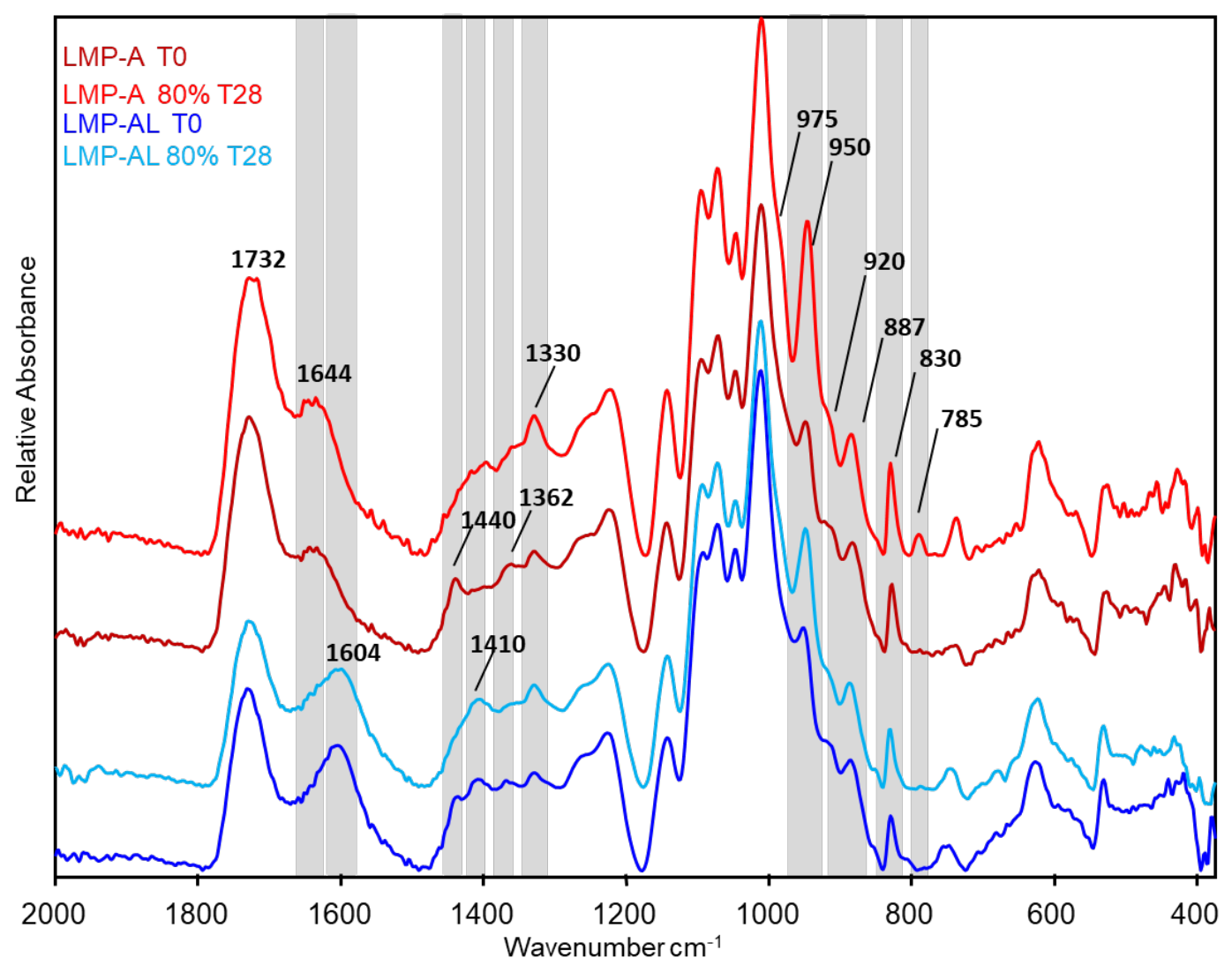

Fig. S4: Alteration in FT-IR spectra after thermal degradation, impact of pectin modification.

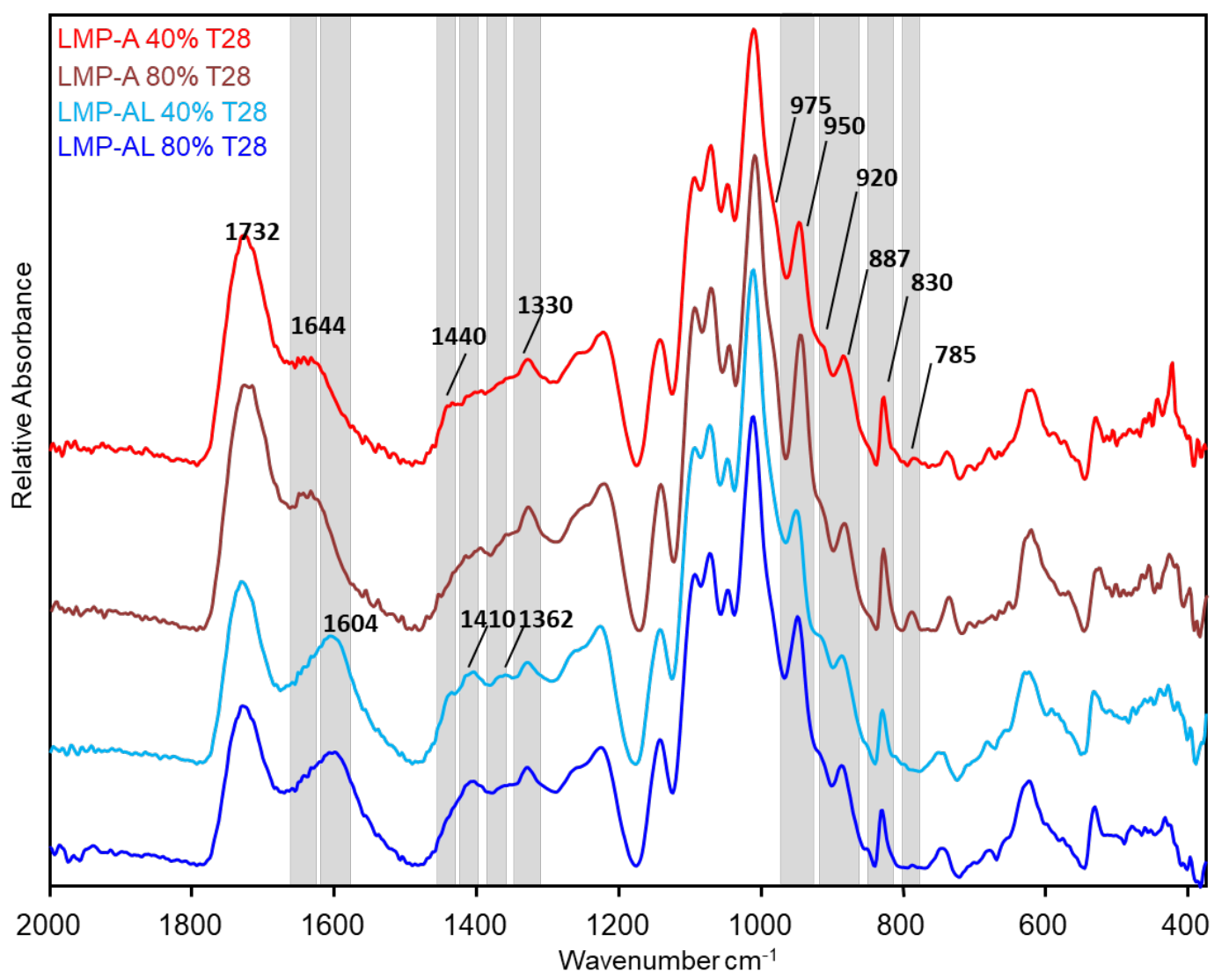

Fig. S5: Alteration in FT-IR spectra after thermal degradation, impact of relative humidity 